NATIONAL LABORATORY

MANAGED BY UT-BATTELLE

FOR THE DEPARTMENT OF ENERGY

\title{
Evaluation of Hanford B Reactor Experiments (PTA-069 and PTA-084) for Code and Data Benchmarking
}

March 18, 2014

\author{
Prepared by \\ Germina Ilas \\ Ian Gauld \\ Robert M. Westfall \\ Marco Pigni
}

Approved for public release:

distribution is unlimited.

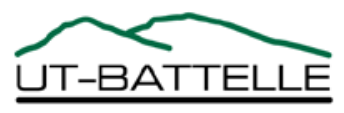




\section{DOCUMENT AVAILABILITY}

Reports produced after January 1, 1996, are generally available free via US Department of Energy (DOE) SciTech Connect.

Website http://www.osti.gov/scitech/

Reports produced before January 1, 1996, may be purchased by members of the public from the following source:

National Technical Information Service

5285 Port Royal Road

Springfield, VA 22161

Telephone 703-605-6000 (1-800-553-6847)

TDD 703-487-4639

Fax 703-605-6900

E-mail info@ntis.gov

Website http://www.ntis.gov/support/ordernowabout.htm

Reports are available to DOE employees, DOE contractors, Energy Technology Data Exchange representatives, and International Nuclear Information System representatives from the following source:

Office of Scientific and Technical Information

PO Box 62

Oak Ridge, TN 37831

Telephone 865-576-8401

Fax 865-576-5728

E-mail reports@osti.gov

Website http://www.osti.gov/contact.html

This report was prepared as an account of work sponsored by an agency of the United States government. Neither the United States government nor any agency thereof, nor any of their employees, makes any warranty, express or implied, or assumes any legal liability or responsibility for the accuracy, completeness, or usefulness of any information, apparatus, product, or process disclosed, or represents that its use would not infringe privately owned rights. Reference herein to any specific commercial product, process, or service by trade name, trademark, manufacturer, or otherwise, does not necessarily constitute or imply its endorsement, recommendation, or favoring by the United States government or any agency thereof. The views and opinions of authors expressed herein do not necessarily state or reflect those of the United States Government or any agency thereof. 


\title{
EVALUATION OF HANFORD B REACTOR EXPERIMENTS (PTA-069 AND PTA-084) FOR CODE AND DATA BENCHMARKING
}

\author{
Germina Ilas \\ Ian Gauld \\ Robert M. Westfall \\ Marco Pigni
}

Date Published: March 18, 2014

Prepared by

OAK RIDGE NATIONAL LABORATORY

Oak Ridge, Tennessee 37831-6283

managed by

UT-BATTELLE, LLC

for the

U.S. DEPARTMENT OF ENERGY

under contract DE-AC05-00OR22725 



\section{CONTENTS}

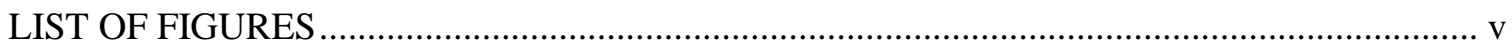

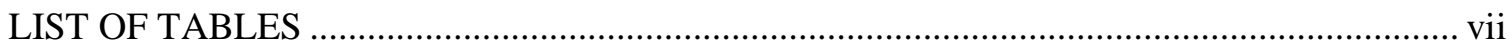

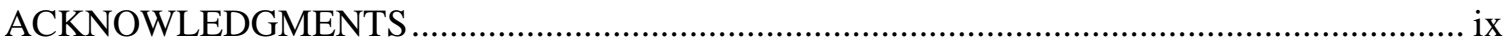

ACRONYMS AND ABBREVIATIONS ...............................................................................

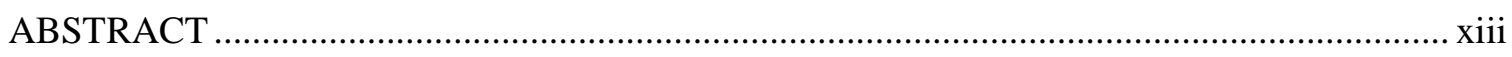

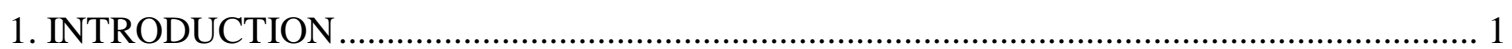

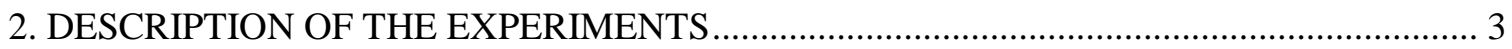

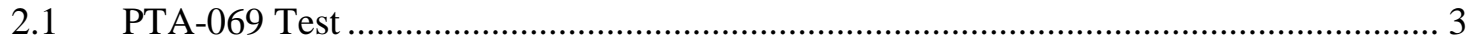

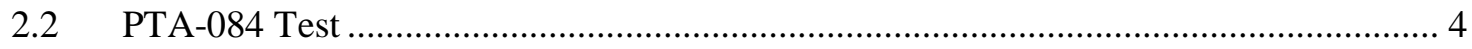

3. HANFORD B FUEL DESIGN AND IRRADIATION DATA................................................ 5

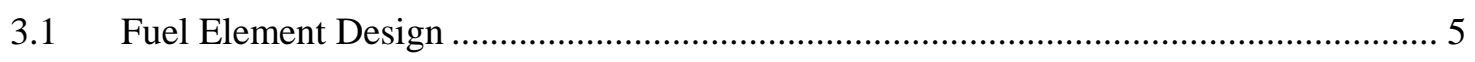

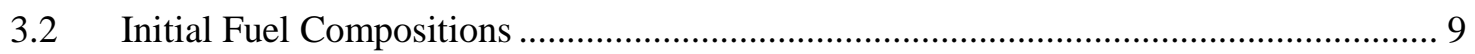

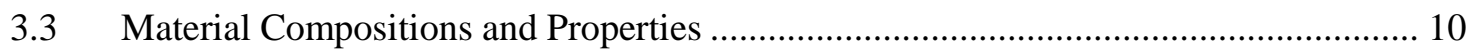

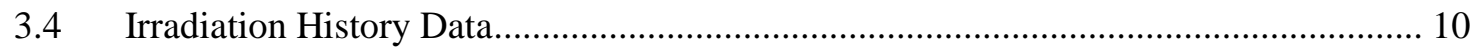

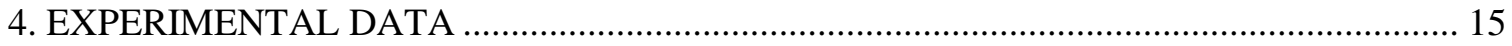

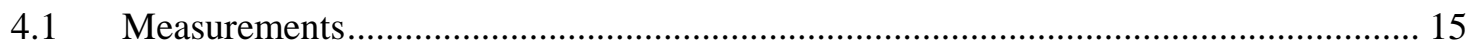

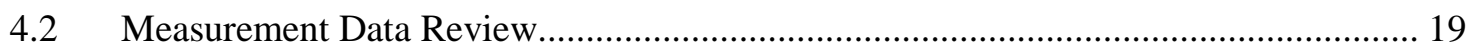

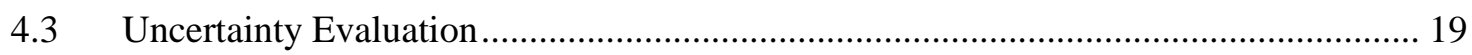

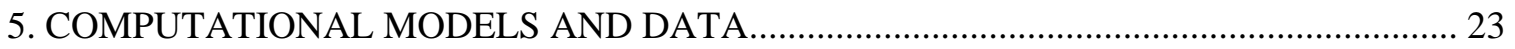

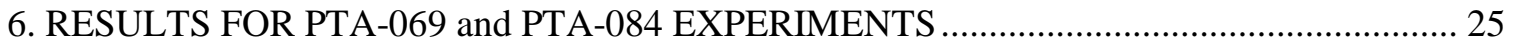

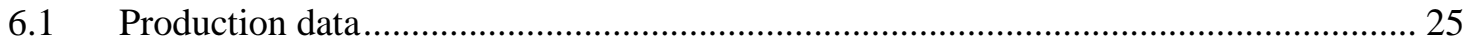

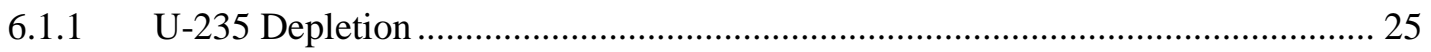

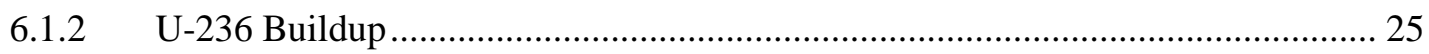

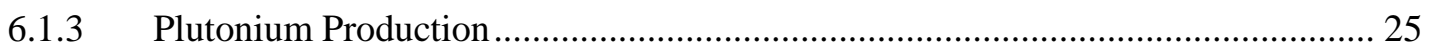

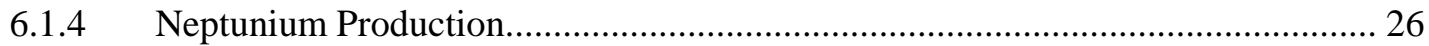

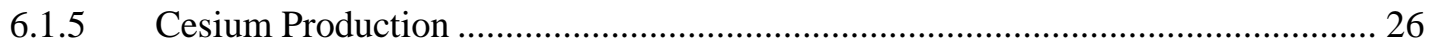

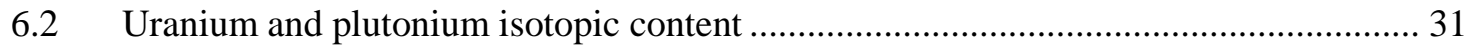

7. DISCUSSION OF RESULTS FOR PTA-069 and PTA-084 EXPERIMENTS ....................... 37

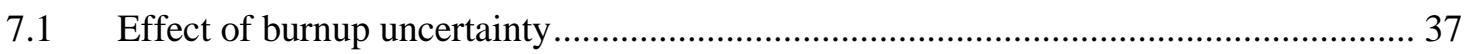

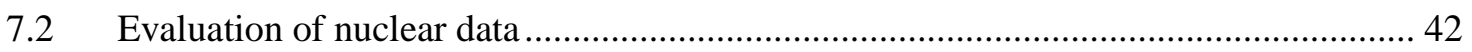

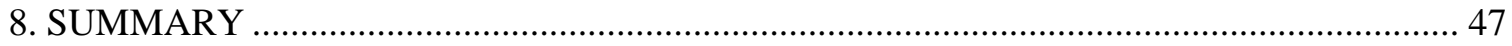

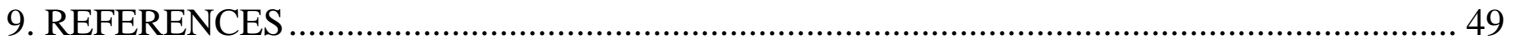

APPENDIX A. ADDITIONAL DATA NEEDS FOR HANFORD B EXPERIMENTS

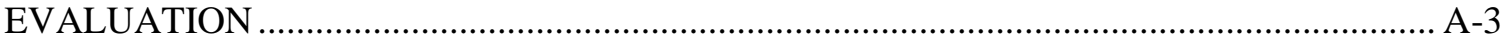

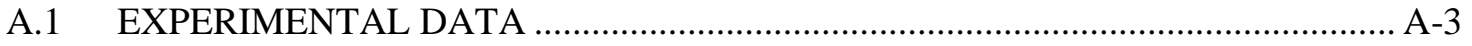




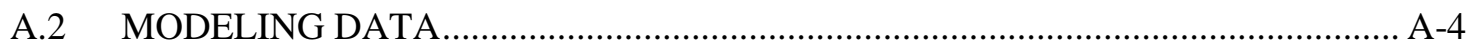

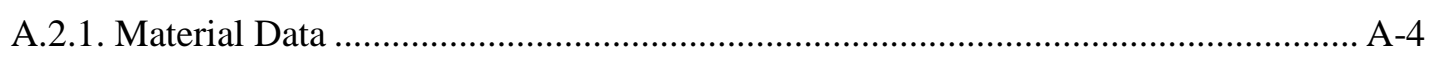

A.2.2. Operation/Irradiation History Data ................................................................. A-4 


\section{LIST OF FIGURES}

Page

Fig. 1. Hanford reactor design [7] showing central graphite core and horizontal irradiation process tubes. 6

Fig. 2. Hanford B reactor front view [7] ......................................................................................... 7

Fig. 3. O3N fuel element design and O3W water mix element (dimensions in Table 2).......................... 8

Fig. 4. Process tube cross section [2] .........................................................................................

Fig. 5. Location map [3] of process tubes in PTA-069 and PTA-084 tests. ............................................. 11

Fig. 6. Computational 2-D lattice model for Hanford B reactor process tube.......................................... 24

Fig. 7. Comparison of calculated and experimental data for ${ }^{235} \mathrm{U}$ depletion.............................................2 27

Fig. 8. Calculated-to-experimental ratio for ${ }^{235} \mathrm{U}$ depletion........................................................... 27

Fig. 9. Comparison of calculated and experimental data for ${ }^{236} \mathrm{U}$ buildup. .............................................. 28

Fig. 10. Calculated-to-experimental ratio for ${ }^{236} \mathrm{U}$ buildup............................................................... 28

Fig. 11. Comparison of calculated and measured data for Pu production. ............................................. 29

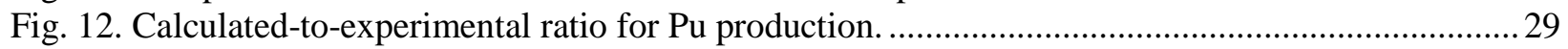

Fig. 13. Comparison of calculated and measured data for Np production................................................ 30

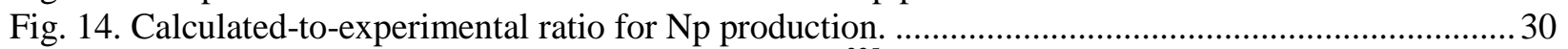

Fig. 15. Comparison of calculated and measured data for ${ }^{235} \mathrm{U}$ isotopic content...................................... 32

Fig. 16. Calculated-to-experimental ratio for ${ }^{235} \mathrm{U}$ isotopic content...................................................... 32

Fig. 17. Comparison of calculated and measured data for ${ }^{236} \mathrm{U}$ isotopic content..................................... 33

Fig. 18. Calculated-to-experimental ratio for ${ }^{236} \mathrm{U}$ isotopic content...................................................... 33

Fig. 19. Comparison of calculated and measured data for ${ }^{239} \mathrm{Pu}$ isotopic content..................................... 34

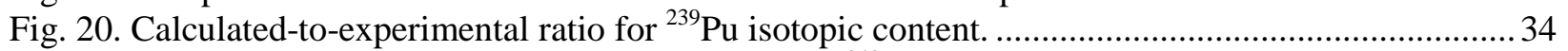

Fig. 21. Comparison of calculated and measured data for ${ }^{240} \mathrm{Pu}$ isotopic content.................................... 35

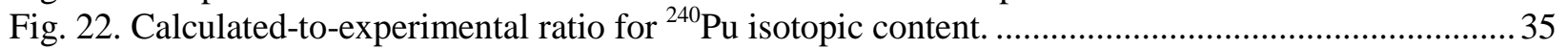

Fig. 23. Variation with nominal burnup of the measured data for cesium.............................................. 38

Fig. 24. Comparison of calculated and experimental data for ${ }^{235} \mathrm{U}$ depletion (Cs burnup)........................... 40

Fig. 25. Comparison of calculated and experimental data for ${ }^{236} \mathrm{U}$ buildup (Cs burnup). ........................... 40

Fig. 26. Comparison of calculated and experimental data for Pu production (Cs burnup)......................... 41

Fig. 27. Comparison of calculated and experimental data for Np production (Cs burnup)........................ 41

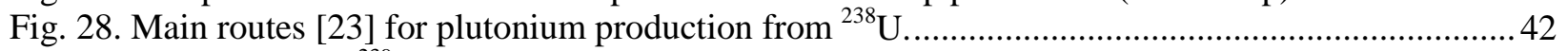

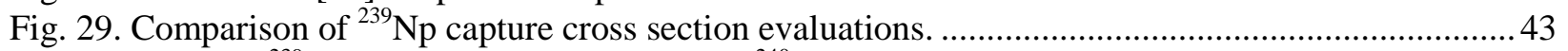

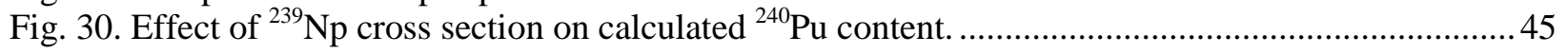




\section{LIST OF TABLES}

Table 1. Fuel element and water mix element design parameters [1] ................................................ 7

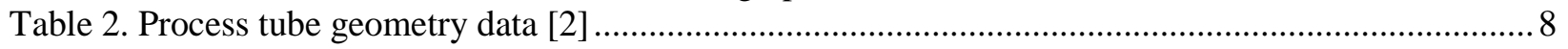

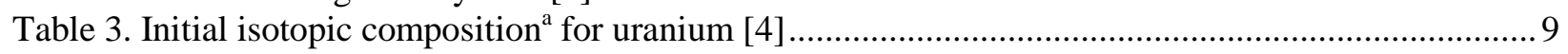

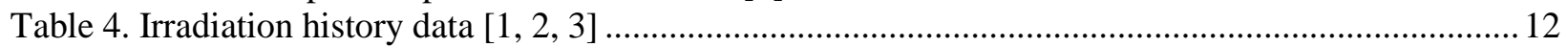

Table 5. Power and exposure data used in simulations for PTA-069 and PTA-084................................. 14

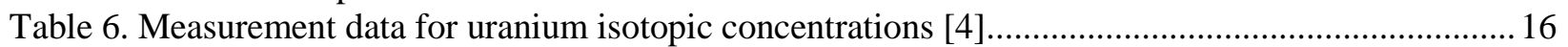

Table 7. Measurement data for plutonium isotopic concentrations [4] ................................................ 17

Table 8. Measurement production data ${ }^{\mathrm{a}}$ for U, Np, Pu and Cs [4] ..................................................... 18

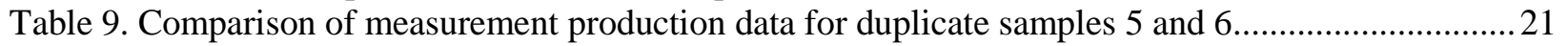

Table 10. Comparison calculation-experiment for $\mathrm{U}$ and $\mathrm{Pu}$ isotopic composition ....................................36

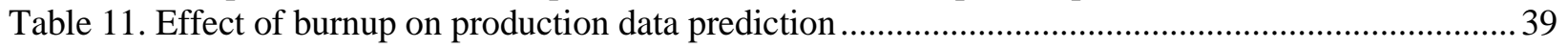

Table 12. Effect of burnup on predicted $U$ and Pu isotopic composition .................................................. 39

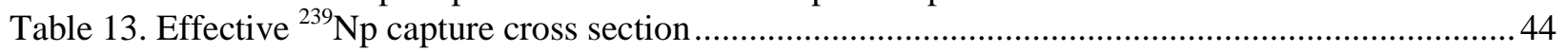




\section{ACKNOWLEDGMENTS}

Funding for this project was provided by the Office of Defense Nuclear Nonproliferation R\&D of the National Nuclear Security Administration in the U.S. Department of Energy (DOE). Review of the manuscript by Eva Sunny and Chuck Weber from the Reactor and Nuclear Systems Division (RNSD) at Oak Ridge National Laboratory, formatting of the document by Angie Alford (RNSD), as well as support provided by Doro Wiarda (RNSD) on SCALE libraries are very much appreciated. Special thanks are extended to Ray Puigh and Scott Finfrock at the DOE Hanford Site for their support with additional references and data for the Hanford reactors. Also, we would like to acknowledge several contributions by Hans Toffer that directly supported the investigations presented here. Hans had a direct role in the Hanford experimental programs conducted in the 1960's and had an early role in collecting the Hanford historic data and making it available for use in studies like those presented in the current report. He later encouraged the DOE Nuclear Criticality Safety Program to support the use of reactor exposure data for investigating and validating neutron cross sections. 



\section{ACRONYMS AND ABBREVIATIONS}

$\begin{array}{ll}2-D & \text { two-dimensional } \\ \text { 3-D } & \text { three-dimensional } \\ \text { C/E } & \text { calculated-to-experimental } \\ \text { DOE } & \text { U.S. Department of Energy } \\ \text { EM } & \text { Office of Environmental Management } \\ \text { LEU } & \text { low-enriched uranium } \\ \text { NCSP } & \text { Nuclear Criticality Safety Program } \\ \text { ORNL } & \text { Oak Ridge National Laboratory } \\ \text { PT } & \text { process tube } \\ \text { RSND } & \text { Reactor and Nuclear Systems Division } \\ \text { SCALE } & \text { Standardized Computer Analyses for Licensing Evaluations }\end{array}$




\begin{abstract}
Experimental data on isotopic concentrations in irradiated nuclear fuel are essential for the validation of computational methods and nuclear data applied in the reactor modeling and simulations used in spent fuel safety and nuclear safeguards. This study investigates the potential use of recently declassified experimental data from the Hanford B reactor as a reactor and spent fuel benchmark. The experiments, performed in 1967, were the first in a series of carefully-designed tests to measure fuel performance and production capabilities at different locations in the reactor and for different exposures. Unlike most spent fuel benchmarks involving commercial fuel, the Hanford B data include unique measurements for very low exposure production fuel, with burnups less than 2,900 MWd/MTU. This report provides an assessment of the measurement data, uncertainties, design data, and operating history documentation, and describes preliminary benchmark models and simulation results. Areas where additional information would improve the quality of the benchmark are identified, as are potentially significant deficiencies in currently available nuclear cross-section data for simulating low-exposure irradiations.
\end{abstract}




\section{INTRODUCTION}

The Hanford production reactors were graphite-moderated and light-water-cooled reactors designed primarily for plutonium production from low-enriched uranium fuel elements and for special isotope production from targets. A series of carefully-designed experiments were conducted in the early-design Hanford reactors to better understand fuel performance and plutonium production quantity and quality. Nuclear data were limited at the time and present-day reactor physics methods were not available; therefore, the predictive capability relied heavily on radiochemistry experiments performed on the discharged fuel elements or irradiation targets to determine the actinide concentration. Many of these experiments were performed with sufficient accuracy and documentation to potentially be used as benchmarks for validation of modern computer codes and evaluated nuclear data libraries for actinide production from low-enriched uranium (LEU).

In the mid-to-late 1990s, many of the primary reports from the Hanford reactors experiments were declassified [1]. In 2010, the US Department of Energy's (DOE) Office of Environmental Management (EM) and Nuclear Criticality Safety Program (NCSP) initiated a multi-laboratory effort to investigate potential use of historical measurement data from the Hanford and Savannah River reactors for burnup code validation and to improve integral actinide cross-section data for the NCSP. The objective of the NCSP was to compile and review available experimental data and determine if sufficient information were available to support use of the experiments to benchmark computer models and nuclear data. Key to the usefulness of these measurement data is the level of detail available in the information that has been publicly released.

A report prepared for DOE/EM that summarizes data from experimental programs focused on production of actinides in the early Hanford reactors was recently issued [2]. Nine separate experiments were identified as having sufficient documentation to be used as potential benchmarks.

The investigations in the current report focus on two experiments from the Hanford B reactor that provide experimental data relevant to plutonium production from LEU fuel. The relevance and adequacy for development of representative computational models of the data documented in the available reports [1, 2, 3, 4] has been reviewed. The current evaluation of the Hanford B experiments extends beyond the objectives of the NCSP program to include: (1) development of computational models based on the available data; (2) interpretation of these data and identification of data that are either inconsistent, missing or otherwise appear errant; (3) identification of areas where additional information would improve the quality of the benchmark; and (4) comparison of preliminary computational results with the measurement data. The comparisons of predicted and measured data provide additional insight into the nuclear data needs that are unique to material production scenarios. The basis for a proposed computational benchmark based on the Hanford B reactor models and data is presented. 


\section{DESCRIPTION OF THE EXPERIMENTS}

Before 1966, the ability to predict isotope transmutation in the Hanford reactors was based on empirical data from isotopic measurements of fuel dissolution experiments. These data were usually obtained from an aggregate of many discharged fuel elements irradiated in different process tubes. Therefore, the data represented an average over a limited number of reactor locations and irradiation times. A series of carefully-designed experiments were later performed to obtain a more refined set of data representative of different locations in the reactor and different irradiation times, covering a wide range of exposure histories. That effort represented the first attempt to quantify the space and time-dependent production capabilities in the Hanford production reactors.

Data from two experiments performed in the Hanford B reactor in 1967 were identified to be highly relevant as benchmarks for production reactors:

1) PTA-069 test: designed to study the production of ${ }^{237} \mathrm{~Np}$ from natural uranium with a high ${ }^{236} \mathrm{U}$ content;

2) PTA-084 test: designed to study production and fuel performance for extended exposures.

These two experiments provided plutonium production data for a total of 19 fuel samples with exposures in the range of 300 to 1,700 MWd/ton $\mathrm{U}(\sim 330$ to $1870 \mathrm{MWd} / \mathrm{MTU})$ and plutonium isotopic concentrations with ${ }^{240} \mathrm{Pu}$ contents of less than $\sim 12 \mathrm{wt} \%$. ${ }^{1}$ In contrast to the Hanford B experimental fuels, a typical commercial fuel achieves a burnup of at least 40,000 MWd/MTU at discharge. Therefore, the Hanford B data are uniquely representative of actinide production for very low burnups in a graphite-moderated reactor.

\subsection{PTA-069 TEST}

The Hanford B measurements performed under the PTA-069 program involved 16 samples from production fuel elements irradiated in five different process tubes (PTs) identified as PT 0582, 1079, 1179, 1078, and 1378, respectively. PTs 0582, 1079, and 1179 contained 32 fuel elements in each tube; PTs 1078 and 1378 operated with 24 fuel elements in the tube. The PTA-069 tubes achieved tube-average nominal exposures of $\sim 300$ to $1700 \mathrm{MWd} /$ ton $\mathrm{U}$ ( 330 to $1870 \mathrm{MWd} / \mathrm{MTU}$ ) as provided by the operator based on water inlet and outlet temperatures. A more detailed analysis of the exposures achieved by each measured fuel element is discussed in Section 3.4.

The PTA-069 experiment was designed to measure the ${ }^{237} \mathrm{~Np}$ production from various uranium precursors in the fuel. The tests were performed using natural uranium fuel with two different initial uranium concentrations: $6 \mathrm{ppm}{ }^{236} \mathrm{U}$ (control fuel) and $400 \mathrm{ppm}{ }^{236} \mathrm{U}$ from recycled uranium. Measurements included destructive analysis of the fuel and mass spectrometry measurements to determine the uranium, plutonium, and neptunium isotopic concentrations, in addition to the concentration of the fission product cesium.

\footnotetext{
${ }^{1}$ Unit of ton is used throughout the experimental reports when specifying uranium mass and exposure; also referred to as a short ton, where 1 ton $=2,000 \mathrm{lb}(907.1847 \mathrm{~kg})$. This unit is converted in many places in the current report to metric ton uranium (MTU), where $1 \mathrm{MTU}=1,000.0 \mathrm{~kg}$.
} 


\section{$2.2 \quad$ PTA-084 TEST}

The measurements performed under the PTA-084 experimental program included three samples from one process tube identified as PT 3485, which operated with 32 fuel elements. This experiment was designed to establish fuel performance limits for extended exposures and assess the capability of the reactor to produce plutonium with high ${ }^{240} \mathrm{Pu}$ contents. The PTA-084 tube achieved a nominal burnup of $1664 \mathrm{MWd} /$ ton U (1834 MWd/MTU). 


\section{HANFORD B FUEL DESIGN AND IRRADIATION DATA}

The Hanford B reactor began operation in 1944 and was designed to produce ${ }^{239} \mathrm{Pu}$ for the US nuclear weapons program. Designed to operate at $250 \mathrm{MW}$, it was the first large scale nuclear reactor. The reactor was graphite-moderated, with a core volume of $1027.6 \mathrm{~m}^{3}(11 \times 8.5 \times 11 \mathrm{~m})$ that contained approximately 2000 MT of graphite. The core had 2,004 horizontal aluminum tubes that contained uranium metal fuel, 29 vertical control rods, and 9 horizontal control rods [5]. The reactor operated with approximately 180-270 MT of LEU metal fuel elements in aluminum cladding, which were loaded in the horizontal tubes (PTs). The reactor was cooled with light water that flowed through the process tubes. The general layout of the reactor core and the arrangement of the PTs and shielding are illustrated in Fig. 1 [6]. A front view of the reactor is presented in Fig. 2 [7].

The design data required for a reactor benchmark include: fuel element geometry and dimensions, configuration of the fuel in the reactor, initial (pre-irradiation) fuel compositions, compositions and temperatures of other major components (i.e., graphite moderator, water coolant), and irradiation data (exposure history and final burnup of the fuel elements).

\subsection{FUEL ELEMENT DESIGN}

Several different fuel designs were used in the Hanford B reactors. Both the PTA-069 and PTA084 experiments used a standard O3N fuel element design. The O3N fuel geometry is annular, enabling water coolant to flow within the fuel as well as outside of it. The cladding is aluminum alloy bonded to the uranium layer by a layer of aluminum-silicon alloy. The fuel element dimensions [1] are listed in Table 1, and the fuel geometry layout [2] is shown in Figs. 3-4.

Aluminum spacers are used to position the fuel elements within the active zone of the PTs in the reactor. These spacers are tubular, with either perforated or solid walls. They are generally 8-in long, although in some cases 5-in-long perforated spacers are used. Process tubes that operated with 32 fuel elements include a non-fuelled O3W water mix element in position 7/32 of the channel. The geometry data for the tubes are presented in Table 2. 


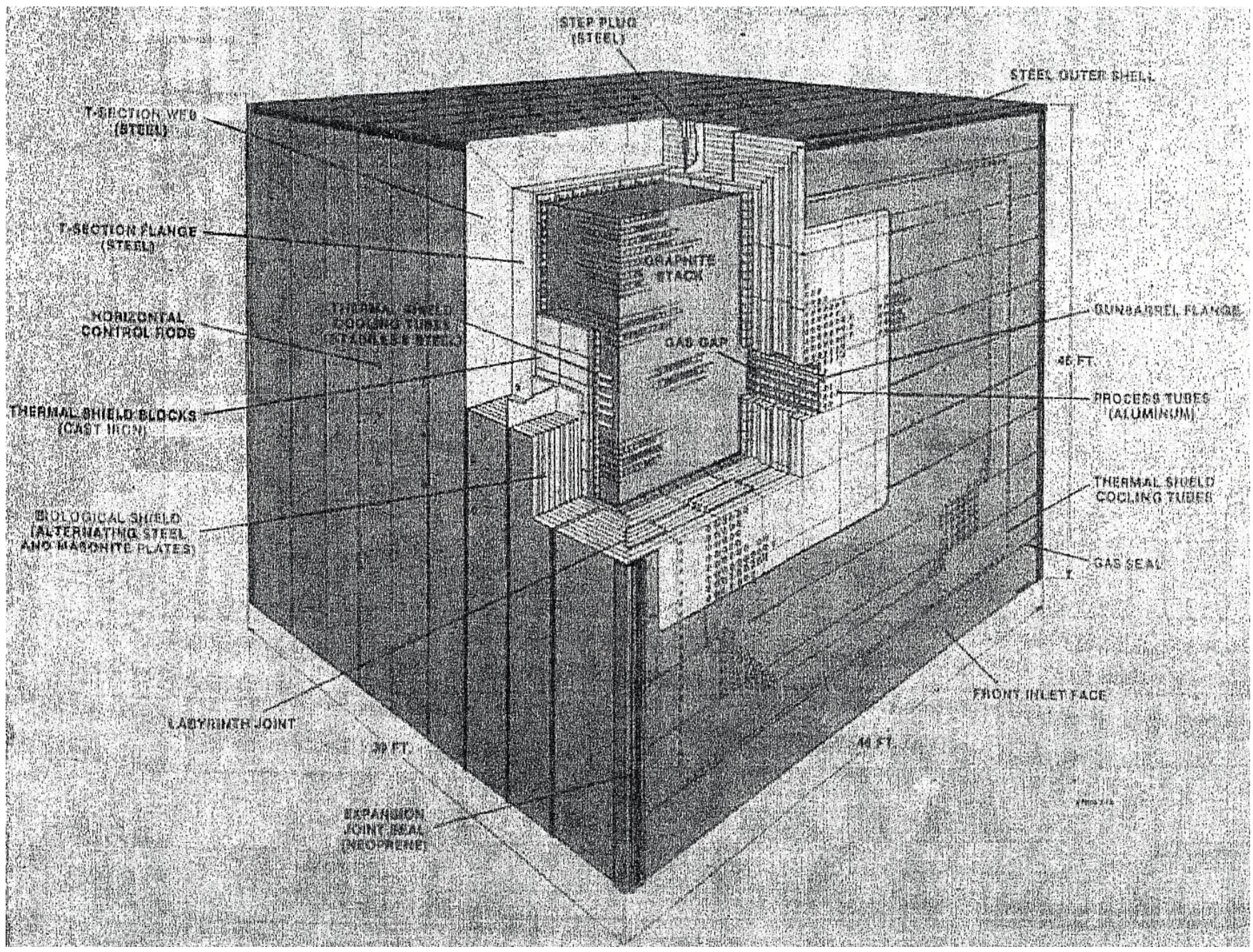

Fig. 1. Hanford reactor design [7] showing central graphite core and horizontal irradiation process tubes. 


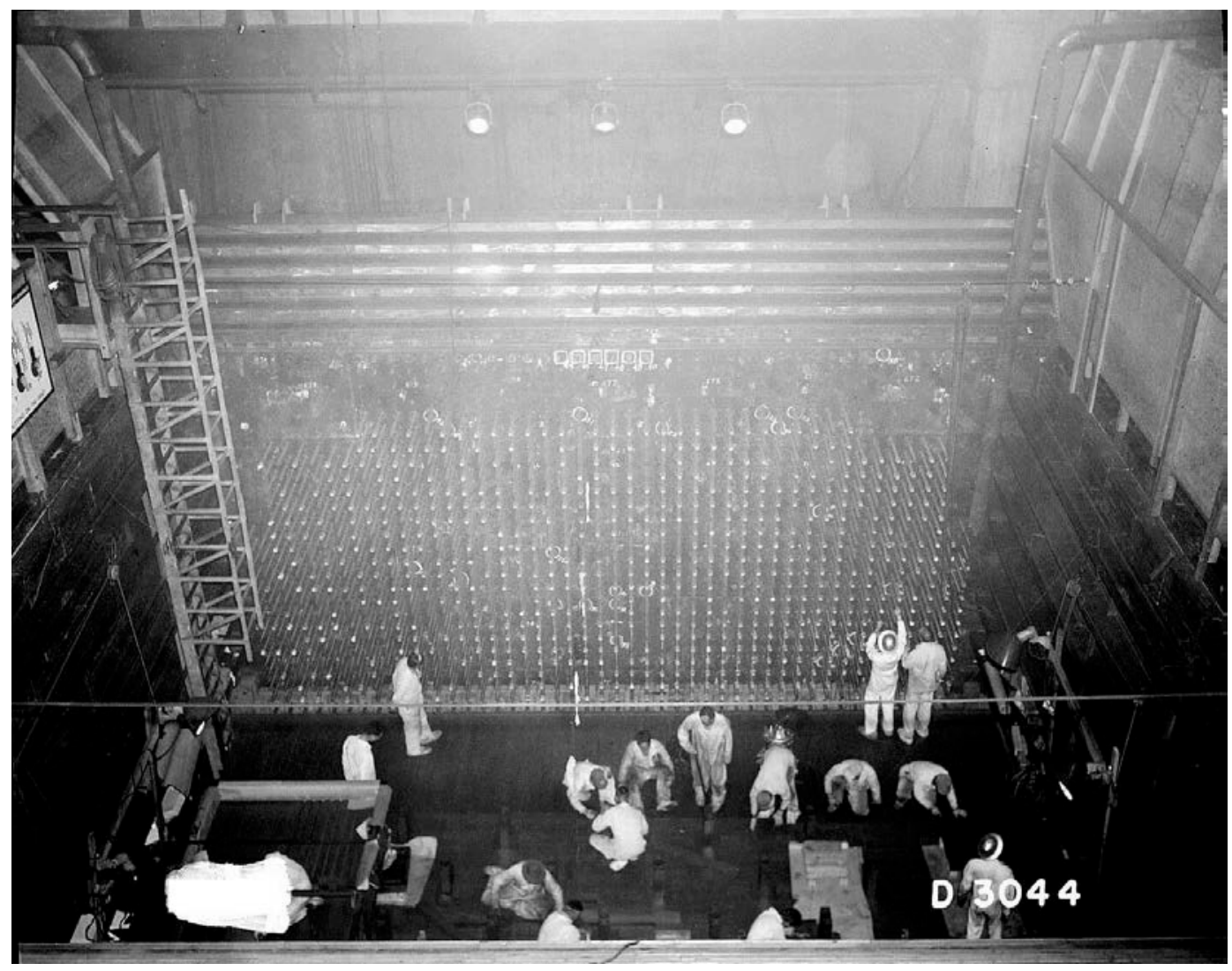

Fig. 2. Hanford B reactor front view [7].

Table 1. Fuel element and water mix element design parameters [1]

\begin{tabular}{|l|c|c|c|}
\hline Parameter & Label $^{\mathbf{a}}$ & O3N fuel element & O3W water mix element \\
\hline Element length (in) & A & $8.965 \pm 0.120$ & $6.640 \pm 0.120$ \\
\hline Fuel length (in) & B & $8.378 \pm 0.010$ & $6.053 \pm 0.010$ \\
\hline Clad outer diameter (in) & C & $1.444 \pm 0.006$ & $1.443 \pm 0.006$ \\
\hline Fuel inner diameter (in) & D & $0.423 \pm 0.004$ & $0.423 \pm 0.004$ \\
\hline Fuel outer diameter (in) & E & $1.356 \pm 0.001$ & $1.356 \pm 0.001$ \\
\hline Clad inner diameter (in) & F & $0.310 \pm 0.006$ & $0.037 \pm 0.006$ \\
\hline Nominal can wall thickness (in) & & $0.037^{\mathrm{b}}$ & 0.037 \\
\hline Nominal spire wall thickness (in) & & 0.050 & 0.050 \\
\hline Weight (with clad) (lb) & & 7.43 & \\
\hline Clad volume (estimated) ${ }^{\mathrm{c}}\left(\mathrm{cm}^{3}\right)$ & & 50.527 & \\
Clad mass (estimated) $(\mathrm{lb})$ & & 0.30 & \\
Fuel volume (estimated) $\left(\mathrm{cm}^{3}\right)$ & & 178.974 & \\
Fuel mass (estimated) $(\mathrm{lb})$ & & 7.13 & \\
Fuel density (estimated) $\left(\mathrm{g} / \mathrm{cm}^{3}\right)$ & & 18.068 & \\
Fuel density (theoretical) $\left(\mathrm{g} / \mathrm{cm}^{3}\right)$ & & 19.1 & \\
\hline
\end{tabular}

${ }^{a}$ Labels refer to Fig. 3.

${ }^{\mathrm{b}}$ Thickness before canning.

' All data labeled "estimated" are based on currently available geometry and mass information. The rest of data in the table are as provided in Ref. 1. 


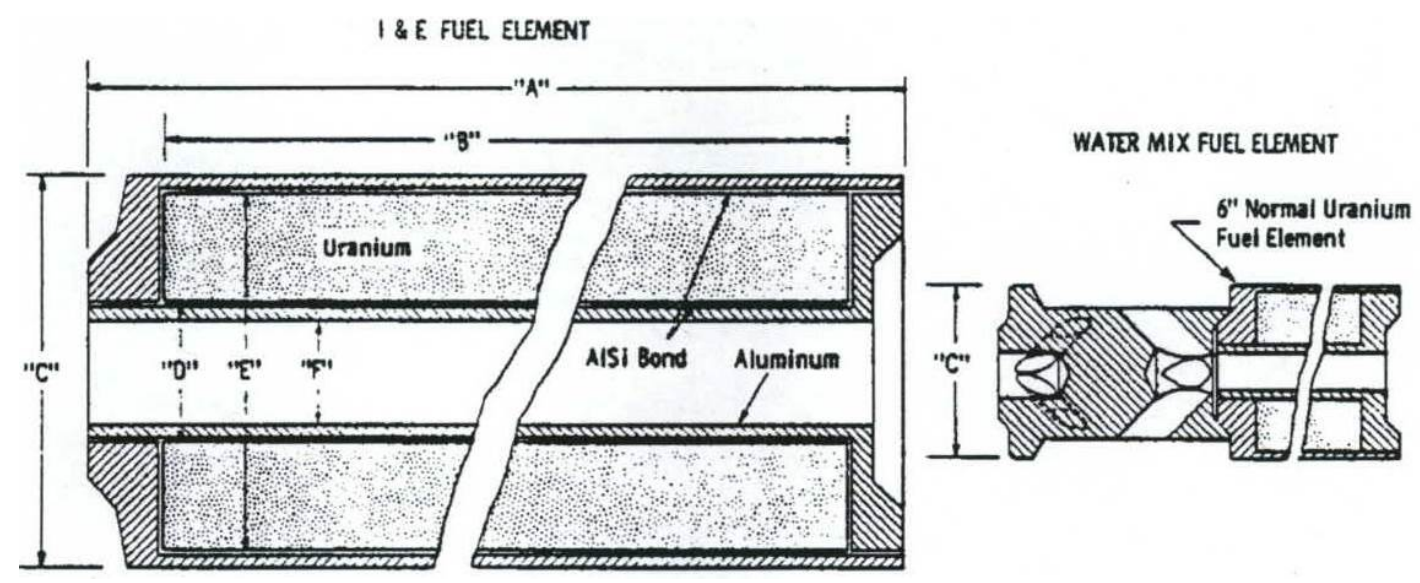

Fig. 3. O3N fuel element design and O3W water mix element (dimensions in Table 2).

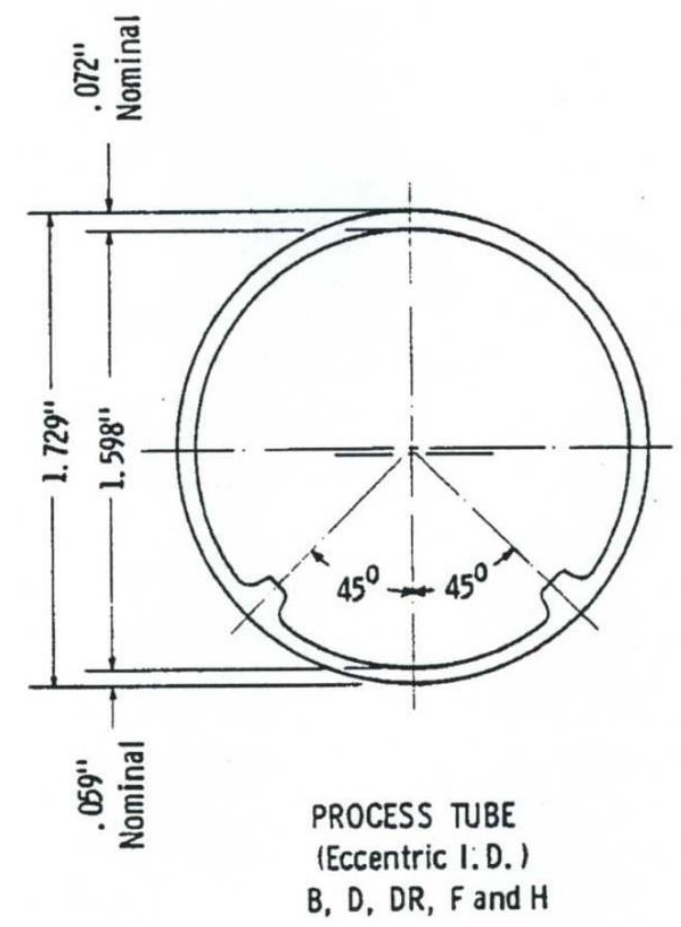

Fig. 4. Process tube cross section [2].

Table 2. Process tube geometry data [2]

\begin{tabular}{|l|c|}
\hline Parameter & Value \\
\hline Lattice geometry & Square pitch \\
Lattice pitch (in) & 8.375 \\
Process tube outer diameter $^{\mathrm{a}}$ (in) & 1.728 \\
Process tube inner diamter (in) & 1.598 \\
\hline
\end{tabular}




\subsection{INITIAL FUEL COMPOSITIONS}

The predominantly used fuel in the Hanford B reactor was natural uranium metal. Two different initial uranium isotopic enrichments were used in the PTA experiments. The three fuel elements in the PTA-084 test used uranium with $0.0006 \mathrm{wt} \%{ }^{236} \mathrm{U}$. The PTA-069 test included eight fuel elements with $0.041 \mathrm{wt} \%{ }^{236} \mathrm{U}$ and eight elements with $0.0006 \mathrm{wt} \%{ }^{236} \mathrm{U}$. The initial fuel compositions for the 19 samples analyzed in this report are shown in Table 3.

The mass of uranium in a fuel element, which is required for a benchmark, was not reported. In the current report, the mass of uranium in a fuel element was derived based on the available geometry data [1, 3], fuel element dimensions (see Fig. 3), and total weight of $7.43 \mathrm{lb}$ [1, 3] for the fuel element including cladding. The mass of aluminum cladding in one fuel element was estimated to be $0.30 \mathrm{lb}$ (136.42 g), yielding a uranium mass per fuel element of $7.13 \mathrm{lb}$ $(3,233.77 \mathrm{~g})$. The estimated density of uranium based on the derived fuel volume is $18.062 \mathrm{~g} / \mathrm{cm}^{3}$. Note that this density is lower than typical values reported [8] for Magnox fuel $\left(18.9 \mathrm{~g} / \mathrm{cm}^{3}\right)$ and less than the theoretical density of $19.1 \mathrm{~g} / \mathrm{cm}^{3}$ for uranium metal.

Table 3. Initial isotopic composition ${ }^{\mathrm{a}}$ for uranium [4]

\begin{tabular}{|c|c|c|c|c|c|c|c|c|}
\hline $\begin{array}{c}\text { Sample } \\
\#\end{array}$ & $\begin{array}{c}\text { Test } \\
\text { number }\end{array}$ & $\begin{array}{c}\text { PT } \\
\text { number }\end{array}$ & $\begin{array}{c}\text { Fuel } \\
\text { element }\end{array}$ & $\begin{array}{c}\text { Sample } \\
\text { ID }\end{array}$ & $\begin{array}{c}\text { U-234 } \\
\text { (wt\%) }\end{array}$ & $\begin{array}{c}\text { U-235 } \\
\text { (wt\%) }\end{array}$ & $\begin{array}{c}\text { U-236 } \\
\text { (wt\%) }\end{array}$ & $\begin{array}{c}\text { U-238 } \\
\text { (wt \%) }\end{array}$ \\
\hline 1 & & 1079 & 11 & $1-1079-11$ & 0.0050 & 0.7119 & 0.0410 & 99.2421 \\
2 & & 1079 & 12 & $2-1079-12$ & 0.0050 & 0.7116 & 0.0006 & 99.2828 \\
3 & & 1079 & 17 & $3-1079-17$ & 0.0050 & 0.7119 & 0.0410 & 99.2421 \\
4 & & 1079 & 18 & $4-1079-18$ & 0.0050 & 0.7116 & 0.0006 & 99.2828 \\
5 & & 1179 & 10 & $5-1179-10$ & 0.0050 & 0.7116 & 0.0006 & 99.2828 \\
6 & & 1179 & 11 & $6-1179-11$ & 0.0050 & 0.7119 & 0.0410 & 99.2421 \\
7 & & 1179 & 16 & $7-1179-16$ & 0.0050 & 0.7116 & 0.0006 & 99.2828 \\
8 & \multirow{2}{*}{ PTA-069 } & 1179 & 17 & $8-1179-17$ & 0.0050 & 0.7119 & 0.0410 & 99.2421 \\
9 & & 1378 & 12 & $9-1378-12$ & 0.0050 & 0.7119 & 0.0410 & 99.2421 \\
10 & & 1378 & 13 & $10-1378-13$ & 0.0050 & 0.7116 & 0.0006 & 99.2828 \\
11 & & 582 & 10 & $11-582-10$ & 0.0050 & 0.7116 & 0.0006 & 99.2828 \\
12 & & 582 & 11 & $12-582-11$ & 0.0050 & 0.7119 & 0.0410 & 99.2421 \\
13 & & 582 & 16 & $13-582-16$ & 0.0050 & 0.7116 & 0.0006 & 99.2828 \\
14 & & 582 & 17 & $14-582-17$ & 0.0050 & 0.7119 & 0.0410 & 99.2421 \\
15 & & 1078 & 12 & $15-1078-12$ & 0.0050 & 0.7116 & 0.0006 & 99.2828 \\
16 & & 1078 & 13 & $16-1078-13$ & 0.0050 & 0.7119 & 0.0410 & 99.2421 \\
\hline 17 & & 3485 & 4 & $17-3485-4$ & 0.0050 & 0.7119 & 0.0006 & 99.2828 \\
18 & PTA-084 & 3485 & 8 & $18-3485-8$ & 0.0050 & 0.7116 & 0.0006 & 99.2828 \\
19 & & 3485 & 17 & $19-3485-17$ & 0.0050 & 0.7116 & 0.0006 & 99.2828 \\
\hline
\end{tabular}

${ }^{a}$ Reported uncertainties in wt\% are: 0.0002 for U-234; 0.00050 for U-235; 0.0010 and 0.0005 for U-236 at content 0.0410 and 0.0006 wt\%, respectively; 0.0020 for U-238. 


\subsection{MATERIAL COMPOSITIONS AND PROPERTIES}

The material compositions, densities, and temperatures affect the neutronic environment of the reactor and the neutron spectrum and therefore the transmutation reaction rates that impact actinide production in the fuel.

The density of the graphite moderator was reported as being between 1.61 and $1.68 \mathrm{~g} / \mathrm{cm}^{3}$ [1]. These values are stated to cover the range of all Hanford reactors and are averaged over the entire reactor volume to include the voids for the process tubes and control rods. The actual graphite density (without voids) was derived using the average of the reported density range $\left(1.645 \mathrm{~g} / \mathrm{cm}^{3}\right)$ and the fraction of the process tube volume in the reactor to obtain the value used in this study of $1.70 \mathrm{~g} / \mathrm{cm}^{3}$. This value is consistent with the density for the Pile Grade A graphite for the Magnox reactor core moderator [8].

No information on impurity levels of the graphite (e.g., trace boron levels) was provided. Therefore trace impurities were not included in the graphite material description. Since impurities can affect the neutron spectrum in the fuel by absorbing thermal neutrons, additional investigation is ongoing to identify representative impurity levels for graphite manufactured at the time.

The density of the aluminum in the structure of the fuel element and process tube is assumed to be $2.7 \mathrm{~g} / \mathrm{cm}^{3}$.

\subsection{IRRADIATION HISTORY DATA}

The locations of the PTs [3] in tests PTA-069 and PTA-084 are illustrated in Fig. 5.

Operating data describing the irradiation history [2, 3] are listed in Table 4. The table includes the following:

a) Sample identification: sample number, PT number, location of the fuel element within the PT;

b) Charge and discharge date of each fuel element and PT;

c) Irradiation time in days and effective full power days;

d) Average power $(\mathrm{kW})$ within each PT;

e) Estimated burnup within the PT (all fuel elements in PT);

f) Water temperature at the PT inlet and outlet;

g) Specific power $(\mathrm{kW} / \mathrm{ft})$ per fuel Pc.

There are no details given in the experimental reports on the significance of the data labeled as specific power "per fuel Pc." It was assumed that the abbreviation "Pc" refers to a fuel piece or fuel element.

Irradiation history data are a key component of a benchmark description. The discharge exposure (burnup) of the fuel element is an essential element of the irradiation history data. Typically in modern experimental programs, burnup is accurately measured using ${ }^{148} \mathrm{Nd}$ as a fission monitor. However, in the PTA-069 and PTA-084 tests only the fission product cesium was measured, though it is not immediately clear if the reported measured cesium refers to the sum of all cesium isotopes present in the samples or just to ${ }^{137} \mathrm{Cs}$ and/or ${ }^{134} \mathrm{Cs}$ that could be measured by gamma scanning. The reported irradiation history data do not provide estimates of the fuel element burnup values. Therefore, the burnup data were derived from other available information. 


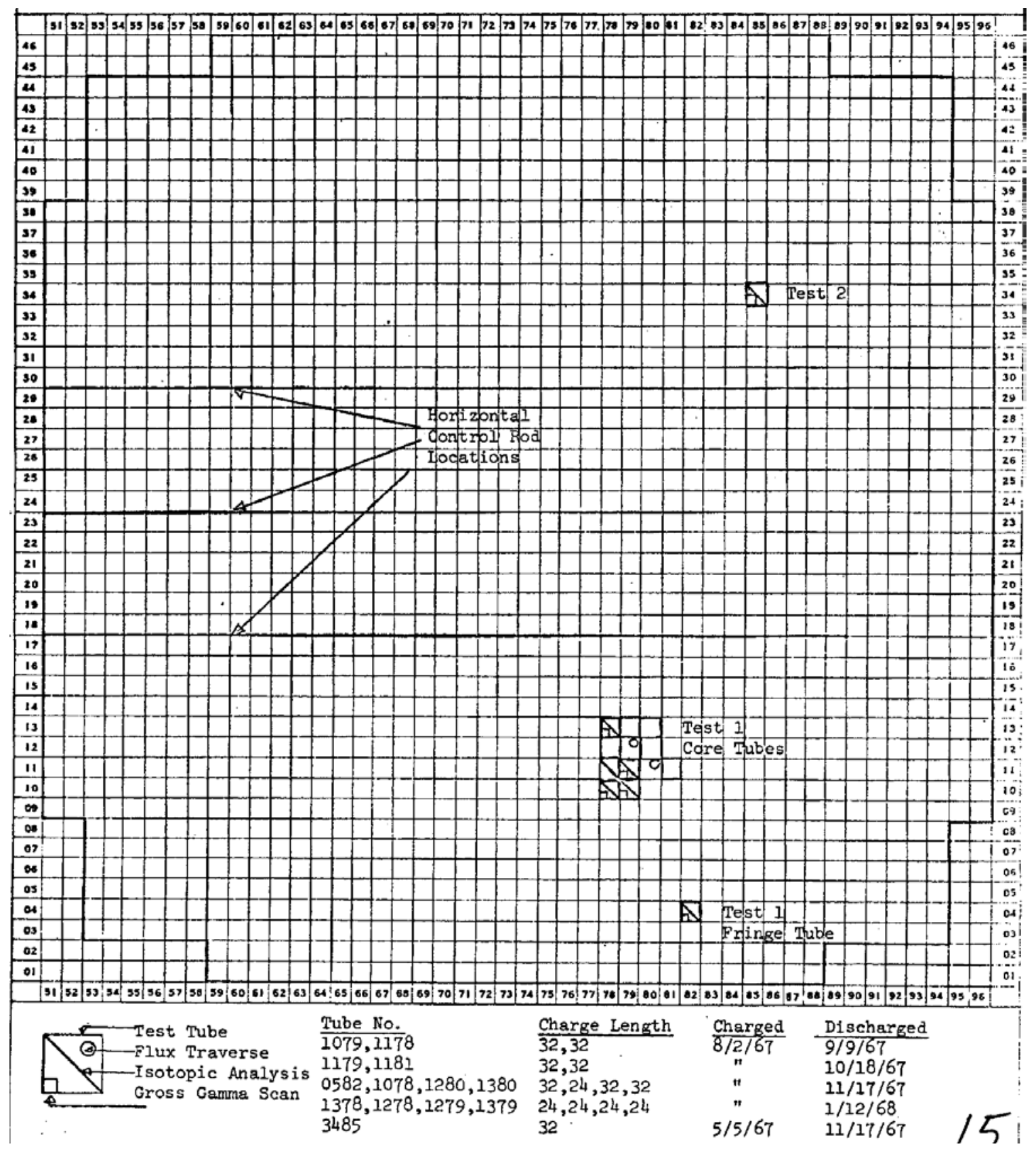

Fig. 5. Location map [3] of process tubes in PTA-069 and PTA-084 tests. 
Table 4. Irradiation history data [1, 2, 3]

\begin{tabular}{|c|c|c|c|c|c|c|c|c|c|c|c|c|}
\hline $\begin{array}{c}\text { Test } \\
\text { number }\end{array}$ & \multirow{2}{*}{$\begin{array}{c}\text { Sample } \\
\text { \# } \\
1\end{array}$} & \multirow{2}{*}{$\begin{array}{c}\begin{array}{c}\text { PT } \\
\text { number }\end{array} \\
1079 \\
\end{array}$} & \multirow{2}{*}{$\begin{array}{c}\begin{array}{c}\text { Fuel } \\
\text { element }\end{array} \\
11\end{array}$} & \multicolumn{2}{|c|}{$\begin{array}{l}\text { Charge and discharge date } \\
\text { (format } \mathbf{m m} / \mathrm{dd} / \mathrm{yy} \text { ) }\end{array}$} & \multirow{5}{*}{$\begin{array}{c}\begin{array}{c}\text { Irradiation } \\
\text { time } \\
\text { (days) }\end{array} \\
38\end{array}$} & \multirow{5}{*}{$\begin{array}{l}\text { FPD }^{a} \\
\text { (days) } \\
30\end{array}$} & \multirow{5}{*}{$\begin{array}{c}\begin{array}{c}\text { Average } \\
\text { PT power } \\
\text { (kW) }\end{array} \\
1059.0\end{array}$} & \multirow{5}{*}{$\begin{array}{c}\begin{array}{c}\text { Estimated } \\
\text { burnup } \\
\text { (MWd/ton }^{b} \text { ) }\end{array} \\
285\end{array}$} & \multicolumn{2}{|c|}{$\begin{array}{l}\text { Water temp. } \\
\quad\left({ }^{\circ} \mathrm{C}\right) \\
\text { inlet outlet }\end{array}$} & \multirow{2}{*}{$\begin{array}{c}\begin{array}{r}\text { Spec. } \\
\mathbf{k W} / \mathbf{f t} \\
\text { fuel Pc. }^{c}\end{array} \\
50.5\end{array}$} \\
\hline \multirow{16}{*}{ PTA-069 } & & & & $8 / 2 / 67$ & 9/9/67 & & & & & 19.9 & 98 & \\
\hline & 2 & 1079 & 12 & & & & & & & & & 50.5 \\
\hline & 3 & 1079 & 17 & & & & & & & & & 76.0 \\
\hline & 4 & 1079 & 18 & & & & & & & & & 76.0 \\
\hline & 5 & 1179 & 10 & $8 / 2 / 67$ & $10 / 18 / 67$ & 77 & 55 & 1167.0 & 575 & 19.2 & 104 & 53.2 \\
\hline & 6 & 1179 & 11 & & & & & & & & & 56.8 \\
\hline & 7 & 1179 & 16 & & & & & & & & & 60.3 \\
\hline & 8 & 1179 & 17 & & & & & & & & & 60.3 \\
\hline & 9 & 1378 & 12 & $8 / 2 / 67$ & $1 / 12 / 68$ & 163 & 116 & 1239.0 & 1721 & 14.4 & 100 & 99.4 \\
\hline & 10 & 1378 & 13 & & & & & & & & & 91.7 \\
\hline & 11 & 582 & 10 & $8 / 2 / 67$ & $11 / 17 / 67$ & 107 & 74 & 911.0 & 607 & 17.3 & 90 & 40.8 \\
\hline & 12 & 582 & 11 & & & & & & & & & 40.8 \\
\hline & 13 & 582 & 16 & & & & & & & & & 56.4 \\
\hline & 14 & 582 & 17 & & & & & & & & & 54.0 \\
\hline & 15 & 1078 & 12 & $8 / 2 / 67$ & $11 / 17 / 67$ & 107 & 74 & 1153.0 & 1011 & 16.3 & 113 & 84.2 \\
\hline & 16 & 1078 & 13 & & & & & & & & & 84.2 \\
\hline \multirow{3}{*}{ PTA-084 } & 17 & 3485 & 4 & $5 / 5 / 67$ & $11 / 17 / 67$ & 196 & 147 & 1262.0 & 1664 & 18.1 & 115 & 28.5 \\
\hline & 18 & 3485 & 8 & & & & & & & & & 52.1 \\
\hline & 19 & 3485 & 17 & & & & & & & & & 85.4 \\
\hline
\end{tabular}

${ }^{\mathrm{b}}$ Ton refers here to short ton; 1 ton $=2000 \mathrm{lbs}(907.1847 \mathrm{~kg}$ or $0.9071847 \mathrm{MTU})$.

"It was assumed that the abbreviation "Pc" in the original reference refers to a fuel piece or fuel element.. 
The water enters the reactor at approximatelly to room temperature (20 C) and exits at a temperature near $100 \mathrm{C}$. The density of water was calculated from pressure-temperature tables [9], considering: (1) a fluid pressure of 417 and 410 psig for the 32-element and 24-element tubes, respectively, as provided in [3]; (2) the inlet and outlet temperatures provided for each process tube [1,3]; and (3) the location of each element in the tube. The estimated water density varied in the range of 0.98 to $1.00 \mathrm{~g} / \mathrm{cm}^{3}$.

The power was continuously measured during operation by monitoring the inlet and outlet temperatures in each PT. The average temperatures during the exposure and the derived process tube powers are listed in Table 5. To obtain the specific power necessary to simulate a fuel element (e.g., W/element or MW/MTU) the mass of uranium in each PT is needed. For a fuel PT containing 32 fuel elements, the total mass of uranium in the PT would be 0.114068 tons ( 1 ton = $2000 \mathrm{lb}$ ), or $0.103481 \mathrm{MTU}$.

To obtain the exposure for a single fuel element, the variation of power within the PT also needs to be considered. Axial neutron flux profiles obtained using activated wires, and gamma scans of irradiated PT elements were available for locations close to the test PTs and can be used to derive the axial power distribution. However, an initial review of the gamma scan and activation data indicated a number of inconsistencies and uncertainties in the data, and additional studies are needed to ensure that the gamma scan data are interpreted correctly. Alternate methods of burnup determination would include using the measured cesium production data for each element or analyzing the measured actinide concentrations using computational methods.

The fuel element burnups derived in this report are based on exposure data provided in Table 4, which include specific power in $\mathrm{kW} / \mathrm{ft}$ for each fuel element $[1,3]$. The power per fuel element, $P_{\text {element }}(\mathrm{kW})$, was calculated as shown in Eq. 1 , where $p_{\text {element }}$ is the specific power $[1,3]$ $(\mathrm{kW} / \mathrm{ft})$ and $l_{\text {element }}$ is the length of the fuel element $(\mathrm{ft})$, which was used to report the linear power. It was assumed that this length is 8.965 in [4].

$$
P_{\text {element }}(k W)=p_{\text {element }}(k W / f t) l_{\text {element }}(f t)
$$

The element specific power $P$ (MW/MTU) was calculated as shown in Eq. 2, where $m_{U}$ is the initial mass of uranium in a fuel element (in MTU). The mass of initial uranium in a fuel element was estimated to be 0.103481 MTU.

$$
P(M W / M T U)=\frac{10^{-3} P_{\text {element }}(k W)}{m_{U}(M T U)}
$$


Table 5. Power and exposure data used in simulations for PTA-069 and PTA-084

\begin{tabular}{|c|c|c|c|c|c|c|c|}
\hline \multirow{2}{*}{$\begin{array}{c}\text { Test } \\
\text { number }\end{array}$} & \multirow{2}{*}{$\begin{array}{c}\text { Sample } \\
\#\end{array}$} & \multirow{2}{*}{$\begin{array}{c}\text { PT } \\
\text { number }\end{array}$} & \multirow{2}{*}{$\begin{array}{c}\text { Fuel } \\
\text { element }\end{array}$} & \multicolumn{2}{|c|}{ Sample specific power } & \multicolumn{2}{|c|}{ Sample exposure } \\
\hline & & & & (kW/element) & (MW/MTU) & (MWd/element) & (MWd/MTU) \\
\hline \multirow[t]{16}{*}{ PTA-069 } & 1 & 1079 & 11 & 37.73 & 11.67 & 1.13 & 350.0 \\
\hline & 2 & 1079 & 12 & 37.73 & 11.67 & 1.13 & 350.0 \\
\hline & 3 & 1079 & 17 & 56.78 & 17.56 & 1.70 & 526.7 \\
\hline & 4 & 1079 & 18 & 56.78 & 17.56 & 1.70 & 526.7 \\
\hline & 5 & 1179 & 10 & 39.74 & 12.29 & 2.19 & 676.0 \\
\hline & 6 & 1179 & 11 & 42.43 & 13.12 & 2.33 & 721.7 \\
\hline & 7 & 1179 & 16 & 45.05 & 13.93 & 2.48 & 766.2 \\
\hline & 8 & 1179 & 17 & 45.05 & 13.93 & 2.48 & 766.2 \\
\hline & 9 & 1378 & 12 & 74.26 & 22.96 & 8.61 & 2663.8 \\
\hline & 10 & 1378 & 13 & 68.51 & 21.19 & 7.95 & 2457.5 \\
\hline & 11 & 582 & 10 & 30.48 & 9.43 & 2.26 & 697.5 \\
\hline & 12 & 582 & 11 & 30.48 & 9.43 & 2.26 & 697.5 \\
\hline & 13 & 582 & 16 & 42.14 & 13.03 & 3.12 & 964.2 \\
\hline & 14 & 582 & 17 & 40.34 & 12.48 & 2.99 & 923.2 \\
\hline & 15 & 1078 & 12 & 62.90 & 19.45 & 4.65 & 1439.5 \\
\hline & 16 & 1078 & 13 & 62.90 & 19.45 & 4.65 & 1439.5 \\
\hline \multirow[t]{3}{*}{ PTA-084 } & 17 & 3485 & 4 & 21.29 & 6.58 & 3.13 & 967.9 \\
\hline & 18 & 3485 & 8 & 38.92 & 12.04 & 5.72 & 1769.4 \\
\hline & 19 & 3485 & 17 & 63.80 & 19.73 & 9.38 & 2900.2 \\
\hline
\end{tabular}




\section{EXPERIMENTAL DATA}

The experimental data for the PTA-069 and PTA-084 test programs [1, 3] include the following measurements:

1. Isotopic concentrations of uranium isotopes ${ }^{234} \mathrm{U},{ }^{235} \mathrm{U},{ }^{236} \mathrm{U}$, and ${ }^{238} \mathrm{U}$ (wt \%);

2. Isotopic concentrations of plutonium isotopes ${ }^{238} \mathrm{Pu},{ }^{239} \mathrm{Pu},{ }^{240} \mathrm{Pu},{ }^{241} \mathrm{Pu}$, and ${ }^{242} \mathrm{Pu}$ (wt \%);

3. Production/depletion quantities for selected elements/isotopes

- $\quad$ total plutonium production (g Pu/ton $\mathrm{U}$ )

- $\quad{ }^{235} \mathrm{U}$ depletion (g ${ }^{235} \mathrm{U}$ depleted/ton $\mathrm{U}$ )

- ${ }^{236} \mathrm{U}$ production (g ${ }^{236} \mathrm{U}$ produced/ton $\left.\mathrm{U}\right)$

- Neptunium production (g Np/ton U)

- Cesium production (atoms Cs/ton U)

\subsection{MEASUREMENTS}

Experimental data are provided as measured values plus associated uncertainties. However, as noted in [1], the meaning of the level of uncertainty is not defined, and is assumed to be the standard deviation associated with the measurements (1 sigma). Several fuel elements reported duplicate measurements made on different samples of the element. These results were used to help confirm the measurements and estimated measurement uncertainties (discussed subsequently).

The fuel isotopic measurements were made using a thin, 1/16 inch thick, radial disc of fuel cut from the center of each fuel element. This fuel sample was dissolved and analyzed by mass spectroscopy to determine the yield and isotopic compositions. The individual heavy elements such as plutonium, uranium, neptunium, and fission products were chemically separated, and isotopic distributions for most of the plutonium and uranium isotopes were measured by mass spectrometry. The ${ }^{238} \mathrm{Pu}$ and neptunium concentrations were measured by alpha counting techniques. The concentrations of plutonium and uranium isotopes were measured using isotope dilution mass spectrometry.

Measurements were performed on the fuel element samples following a cooling period after discharge from the reactor. The cooling time (or date of measurements) was not reported. Because isotopic concentrations change after discharge due to decay or production from decay precursors, this information is required for accurate modeling. Information on the Hanford reactors operations suggests that typically the cooling time before processing varies from about 90 days to 1 year. Uncertainties in the measurement date have the largest impact on calculated

${ }^{241} \mathrm{Pu}$ (5-10\%), due to its half-life of about 14 years. Other plutonium isotopes can be affected by $1-2 \%$ from the cooling time uncertainties. Specific information relevant to the PTA-069 test indicates $[10,11]$ that most likely the measurements for the samples from this test were performed at approximately two months after discharge. In the current report, a two-month cooling time was assumed for the analyzed samples.

Tables 6 and 7 list the measured isotopic fractions as reported [4] for uranium and plutonium, respectively. Absolute values for actinide and cesium production data are available [4] for ${ }^{235} \mathrm{U}$ (as g of depleted ${ }^{235} U$ per ton of $U$ ), ${ }^{236} U$ (as ${ }^{236} U$ buildup in ppm per ton of $U$ ), total Pu content (as g of Pu per ton of $\mathrm{U}$ ), and Cs content (as g of Cs per ton $\mathrm{U}$ ). These measured production data as reported are listed in Table 8 . Note that samples identified as 5* and 6* in Tables 6-8 are repeat measurements [4] of samples 5 and 6. 
Table 6. Measurement data for uranium isotopic concentrations [4]

\begin{tabular}{|c|c|c|c|c|c|c|c|c|c|c|c|c|c|c|c|}
\hline \multirow{2}{*}{$\begin{array}{l}\text { Sample } \\
\text { number }\end{array}$} & \multirow{2}{*}{$\begin{array}{c}\text { PT } \\
\text { number }\end{array}$} & \multirow{2}{*}{$\begin{array}{c}\text { Fuel } \\
\text { element }\end{array}$} & \multirow{2}{*}{$\begin{array}{c}\text { Nominal } \\
\text { burnup } \\
\text { (MWd/MTU) }^{\text {b }}\end{array}$} & \multicolumn{3}{|c|}{${ }^{234} \mathbf{U}$} & \multicolumn{3}{|c|}{${ }^{235} \mathbf{U}$} & \multicolumn{3}{|c|}{${ }^{236} \mathbf{U}$} & \multicolumn{3}{|c|}{${ }^{238} \mathbf{U}$} \\
\hline & & & & $\begin{array}{c}\text { content } \\
\text { (wt \%) }\end{array}$ & $\begin{array}{l}\text { error } \\
\text { (wt\%) }\end{array}$ & $\begin{array}{c}\text { rel } \\
\text { error }^{\mathrm{a}} \\
(\%) \\
\end{array}$ & $\begin{array}{c}\text { content } \\
\text { (wt \%) }\end{array}$ & $\begin{array}{c}\text { error } \\
\text { (wt\%) }\end{array}$ & $\begin{array}{c}\text { rel } \\
\text { error } \\
(\%)\end{array}$ & $\begin{array}{c}\text { content } \\
\text { (wt\%) }\end{array}$ & $\begin{array}{l}\text { error } \\
\text { (wt\%) }\end{array}$ & $\begin{array}{c}\text { rel } \\
\text { error } \\
(\%)\end{array}$ & $\begin{array}{c}\text { content } \\
\text { (wt \%) }\end{array}$ & $\begin{array}{l}\text { error } \\
\text { (wt\%) }\end{array}$ & $\begin{array}{c}\text { rel } \\
\text { error } \\
(\%)\end{array}$ \\
\hline 1 & 1079 & 11 & 350.0 & 0.00618 & 0.00060 & 9.7 & 0.6855 & 0.0070 & 1.0 & 0.04857 & 0.00100 & 2.1 & 99.2617 & 0.0070 & 0.0 \\
\hline 2 & 1079 & 12 & 350.0 & 0.00510 & 0.00040 & 7.8 & 0.6690 & 0.0030 & 0.4 & 0.00730 & 0.00030 & 4.1 & 99.3190 & 0.0030 & 0.0 \\
\hline 3 & 1079 & 17 & 526.7 & 0.00620 & 0.00050 & 8.1 & 0.6650 & 0.0030 & 0.5 & 0.04700 & 0.00100 & 2.1 & 99.2810 & 0.0030 & 0.0 \\
\hline 4 & 1079 & 18 & 526.7 & 0.00510 & 0.00040 & 7.8 & 0.6600 & 0.0030 & 0.5 & 0.00840 & 0.00100 & 11.9 & 99.3270 & 0.0030 & 0.0 \\
\hline 5 & 1179 & 10 & 676.0 & 0.00530 & 0.00030 & 5.7 & 0.6440 & 0.0040 & 0.6 & 0.01280 & 0.00050 & 3.9 & 99.3380 & 0.0040 & 0.0 \\
\hline 6 & 1179 & 11 & 721.7 & 0.00720 & 0.00070 & 9.7 & 0.6400 & 0.0040 & 0.6 & 0.05200 & 0.00100 & 1.9 & 99.3000 & 0.0040 & 0.0 \\
\hline 7 & 1179 & 16 & 766.2 & 0.00530 & 0.00050 & 9.4 & 0.6190 & 0.0030 & 0.5 & 0.01540 & 0.00040 & 2.6 & 99.3600 & 0.0030 & 0.0 \\
\hline 8 & 1179 & 17 & 766.2 & 0.00610 & 0.00060 & 9.8 & 0.6180 & 0.0030 & 0.5 & 0.05400 & 0.00100 & 1.9 & 99.3210 & 0.0030 & 0.0 \\
\hline 9 & 1378 & 12 & 2663.8 & 0.00740 & 0.00050 & 6.8 & 0.5230 & 0.0040 & 0.8 & 0.07000 & 0.00100 & 1.4 & 99.3990 & 0.0050 & 0.0 \\
\hline 10 & 1378 & 13 & 2457.5 & 0.00530 & 0.00060 & 11.3 & 0.5140 & 0.0040 & 0.8 & 0.03200 & 0.00060 & 1.9 & 99.4490 & 0.0040 & 0.0 \\
\hline 11 & 582 & 10 & 697.5 & 0.00610 & 0.00030 & 4.9 & 0.6480 & 0.0040 & 0.6 & 0.01120 & 0.00050 & 4.5 & 99.3350 & 0.0040 & 0.0 \\
\hline 12 & 582 & 11 & 697.5 & 0.00620 & 0.00030 & 4.8 & 0.6170 & 0.0040 & 0.6 & 0.05500 & 0.00050 & 0.9 & 99.3220 & 0.0040 & 0.0 \\
\hline 13 & 582 & 16 & 964.2 & 0.00530 & 0.00020 & 3.8 & 0.6190 & 0.0040 & 0.6 & 0.01620 & 0.00050 & 3.1 & 99.3600 & 0.0030 & 0.0 \\
\hline 14 & 582 & 17 & 923.2 & 0.00640 & 0.00030 & 4.7 & 0.6290 & 0.0040 & 0.6 & 0.05300 & 0.00050 & 0.9 & 99.3120 & 0.0030 & 0.0 \\
\hline 15 & 1078 & 12 & 1439.5 & 0.00550 & 0.00020 & 3.6 & 0.5860 & 0.0040 & 0.7 & 0.02020 & 0.00060 & 3.0 & 99.3880 & 0.0040 & 0.0 \\
\hline 16 & 1078 & 13 & 1439.5 & 0.00620 & 0.00020 & 3.2 & 0.5880 & 0.0040 & 0.7 & 0.05990 & 0.00080 & 1.3 & 99.3460 & 0.0040 & 0.0 \\
\hline 17 & 3485 & 4 & 967.9 & 0.00500 & 0.00050 & 10.0 & 0.6340 & 0.0030 & 0.5 & 0.01290 & 0.00050 & 3.9 & 99.3500 & 0.0030 & 0.0 \\
\hline 18 & 3485 & 8 & 1769.4 & 0.00500 & 0.00020 & 4.0 & 0.5700 & 0.0030 & 0.5 & 0.02300 & 0.00090 & 3.9 & 99.4000 & 0.0030 & 0.0 \\
\hline 19 & 3485 & 17 & 2900.2 & 0.00500 & 0.00030 & 6.0 & 0.4850 & 0.0030 & 0.6 & 0.03620 & 0.00080 & 2.2 & 99.4700 & 0.0030 & 0.0 \\
\hline $5^{* c}$ & 1179 & 10 & 676.0 & 0.00540 & 0.00030 & 5.6 & 0.6310 & 0.0040 & 0.6 & 0.01300 & 0.00050 & 3.8 & 99.3500 & 0.0040 & 0.0 \\
\hline $6 *$ & 1179 & 11 & 721.7 & 0.00670 & 0.00070 & 10.4 & 0.6330 & 0.0040 & 0.6 & 0.05200 & 0.00100 & 1.9 & 99.3100 & 0.0040 & 0.0 \\
\hline
\end{tabular}

a Relative measurement error is calculated as the ratio (in \%) of the reported $\mathrm{m}$
${ }^{\mathrm{b}}$ Derived based on data from primary references, as discussed in Section 3.4 .

Derived based on data from primary references, as discussed in Section 3.4 .
“ Samples $5^{*}$ and $6^{*}$ are reported as duplicate measurements for samples 5 and 6 , respectively. 
Table 7. Measurement data for plutonium isotopic concentrations [4]

\begin{tabular}{|c|c|c|c|c|c|c|c|c|c|c|c|c|c|c|c|c|c|}
\hline \multirow{2}{*}{$\begin{array}{l}\text { Sample } \\
\text { number }\end{array}$} & \multirow{2}{*}{$\begin{array}{c}\text { PT } \\
\text { number }\end{array}$} & \multirow{2}{*}{$\begin{array}{c}\text { Fuel } \\
\text { element }\end{array}$} & \multicolumn{3}{|c|}{${ }^{238} \mathbf{P u}$} & \multicolumn{3}{|c|}{${ }^{239} \mathbf{P u}$} & \multicolumn{3}{|c|}{${ }^{240} \mathbf{P u}$} & \multicolumn{3}{|c|}{${ }^{{ }^{241} \mathbf{P u}}$} & \multicolumn{3}{|c|}{${ }^{{ }^{242} \mathbf{P u}}$} \\
\hline & & & $\begin{array}{c}\text { content } \\
\text { (wt\%) }\end{array}$ & $\begin{array}{c}\text { error } \\
\text { (wt\%) }\end{array}$ & $\begin{array}{c}\text { rel } \\
\text { error }^{\mathrm{a}} \\
(\%)\end{array}$ & $\begin{array}{c}\text { content } \\
(w t \%)\end{array}$ & $\begin{array}{c}\text { error } \\
\text { (wt\%) }\end{array}$ & $\begin{array}{c}\text { rel } \\
\text { error } \\
(\%)\end{array}$ & $\begin{array}{c}\text { content } \\
(\mathrm{wt} \%)\end{array}$ & $\begin{array}{c}\text { error } \\
\text { (wt\%) }\end{array}$ & $\begin{array}{c}\text { rel } \\
\text { error } \\
(\%)\end{array}$ & $\begin{array}{c}\text { content } \\
\text { (wt \%) }\end{array}$ & $\begin{array}{c}\text { error } \\
\text { (wt\%) }\end{array}$ & $\begin{array}{c}\text { rel } \\
\text { error } \\
(\%)\end{array}$ & $\begin{array}{c}\text { content } \\
(\mathrm{wt} \%)\end{array}$ & $\begin{array}{c}\text { error } \\
\text { (wt\%) }\end{array}$ & $\begin{array}{c}\text { rel } \\
\text { error } \\
(\%)\end{array}$ \\
\hline 1 & 1079 & 11 & 0.0094 & 0.0010 & 10.64 & 96.5860 & 0.0200 & 0.02 & 3.2520 & 0.0200 & 0.62 & 0.1678 & 0.0050 & 2.98 & 0.01240 & 0.00100 & 8.06 \\
\hline 2 & 1079 & 12 & 0.0059 & 0.0006 & 10.17 & 96.5300 & 0.0200 & 0.02 & 3.3400 & 0.0200 & 0.60 & 0.1320 & 0.0030 & 2.27 & 0.00000 & 0.00000 & 0.00 \\
\hline 3 & 1079 & 17 & 0.0067 & 0.0007 & 10.45 & 96.1300 & 0.0200 & 0.02 & 3.6600 & 0.0200 & 0.55 & 0.1610 & 0.0060 & 3.73 & 0.00500 & 0.01000 & 200.00 \\
\hline 4 & 1079 & 18 & 0.0043 & 0.0004 & 9.30 & 95.8300 & 0.0400 & 0.04 & 4.0000 & 0.0400 & 1.00 & 0.1730 & 0.0090 & 5.20 & 0.00000 & 0.00000 & 0.00 \\
\hline 5 & 1179 & 10 & 0.0000 & 0.0010 & NA & 93.2200 & 0.0300 & 0.03 & 6.3450 & 0.0300 & 0.47 & 0.4200 & 0.0080 & 1.90 & 0.01200 & 0.01000 & 83.33 \\
\hline 6 & 1179 & 11 & 0.0000 & 0.0015 & NA & 93.5600 & 0.0300 & 0.03 & 6.0220 & 0.0300 & 0.50 & 0.4010 & 0.0080 & 2.00 & 0.01300 & 0.00100 & 7.69 \\
\hline 7 & 1179 & 16 & 0.0120 & 0.0012 & 10.00 & 92.1300 & 0.0400 & 0.04 & 7.2700 & 0.0400 & 0.55 & 0.5800 & 0.0100 & 1.72 & 0.01900 & 0.00200 & 10.53 \\
\hline 8 & 1179 & 17 & 0.0200 & 0.0020 & 10.00 & 91.9900 & 0.0400 & 0.04 & 7.3900 & 0.0400 & 0.54 & 0.5900 & 0.0100 & 1.69 & 0.02100 & 0.00400 & 19.05 \\
\hline 9 & 1378 & 12 & 0.0550 & 0.0055 & 10.00 & 82.2600 & 0.0800 & 0.10 & 15.3700 & 0.0800 & 0.52 & 2.1800 & 0.0100 & 0.46 & 0.18500 & 0.00600 & 0.19 \\
\hline 10 & 1378 & 13 & 0.0330 & 0.0033 & 10.00 & 82.3700 & 0.0800 & 0.10 & 15.2800 & 0.0800 & 0.52 & 2.1700 & 0.0100 & 0.46 & 0.18700 & 0.00600 & 0.19 \\
\hline 11 & 582 & 10 & 0.0095 & 0.0010 & 10.53 & 95.0900 & 0.0300 & 0.03 & 4.6400 & 0.0300 & 0.65 & 0.2610 & 0.0020 & 0.77 & 0.00760 & 0.00700 & 92.11 \\
\hline 12 & 582 & 11 & 0.0190 & 0.0019 & 10.00 & 92.5300 & 0.0300 & 0.03 & 6.8800 & 0.0300 & 0.44 & 0.5720 & 0.0030 & 0.52 & 0.02000 & 0.00100 & 5.00 \\
\hline 13 & 582 & 16 & 0.0120 & 0.0012 & 10.00 & 92.4900 & 0.0300 & 0.03 & 6.9000 & 0.0300 & 0.43 & 0.5740 & 0.0050 & 0.87 & 0.02900 & 0.00200 & 6.90 \\
\hline 14 & 582 & 17 & 0.0150 & 0.0015 & 10.00 & 93.6800 & 0.0300 & 0.03 & 5.8800 & 0.0300 & 0.51 & 0.4280 & 0.0040 & 0.93 & 0.01800 & 0.00100 & 5.56 \\
\hline 15 & 1078 & 12 & 0.0150 & 0.0015 & 10.00 & 89.8100 & 0.0500 & 0.06 & 9.2200 & 0.0500 & 0.54 & 0.9220 & 0.0050 & 0.54 & 0.04300 & 0.00100 & 0.19 \\
\hline 16 & 1078 & 13 & 0.0270 & 0.0027 & 10.00 & 89.5400 & 0.0500 & 0.06 & 9.4600 & 0.0500 & 0.53 & 0.9510 & 0.0050 & 0.53 & 0.04400 & 0.00100 & 0.19 \\
\hline 17 & 3485 & 4 & 0.0084 & 0.0005 & 5.95 & 94.2300 & 0.0300 & 0.03 & 5.3800 & 0.0300 & 0.56 & 0.3720 & 0.0020 & 0.54 & 0.00910 & 0.00050 & 0.19 \\
\hline 18 & 3485 & 8 & 0.0170 & 0.0020 & 11.76 & 88.8100 & 0.0500 & 0.06 & 10.1400 & 0.0500 & 0.49 & 0.9800 & 0.0050 & 0.51 & 0.05400 & 0.00200 & 0.19 \\
\hline 19 & 3485 & 17 & 0.0430 & 0.0050 & 11.63 & 79.2000 & 0.1000 & 0.13 & 17.9000 & 0.1000 & 0.56 & 2.5100 & 0.0200 & 0.80 & 0.31700 & 0.00300 & 0.19 \\
\hline $5^{* b}$ & 1179 & 10 & 0.0097 & 0.0010 & 10.31 & 93.1300 & 0.0300 & 0.03 & 6.3400 & 0.0300 & 0.47 & 0.4180 & 0.0080 & 1.91 & 0.01100 & 0.01000 & 90.91 \\
\hline $6^{*}$ & 1179 & 11 & 0.0150 & 0.0020 & 13.33 & 93.5300 & 0.0300 & 0.03 & 6.0500 & 0.0300 & 0.50 & 0.4080 & 0.0080 & 1.96 & 0.01000 & 0.01000 & 100.00 \\
\hline
\end{tabular}

Samples $5^{*}$ and $6^{*}$ are reported as duplicate measurements for samples 5 and 6 , respectively. 
Table 8. Measurement production data ${ }^{a}$ for U, Np, Pu and Cs [4]

\begin{tabular}{|c|c|c|c|c|c|c|c|c|c|c|c|c|c|c|c|c|c|}
\hline \multirow[t]{2}{*}{$\begin{array}{l}\text { Sample } \\
\text { number }\end{array}$} & \multirow[t]{2}{*}{$\begin{array}{c}\text { PT } \\
\text { number }\end{array}$} & \multirow[t]{2}{*}{$\begin{array}{l}\text { Fuel } \\
\text { element }\end{array}$} & \multicolumn{3}{|c|}{$\begin{array}{c}{ }^{235} \mathrm{U} \\
\text { depletion }\end{array}$} & \multicolumn{3}{|c|}{$\begin{array}{c}{ }^{236} \mathrm{U} \\
\text { buildup }\end{array}$} & \multicolumn{3}{|c|}{$\begin{array}{c}\mathrm{Np} \\
\text { production }\end{array}$} & \multicolumn{3}{|c|}{$\begin{array}{c}\text { Pu } \\
\text { production }\end{array}$} & \multicolumn{3}{|c|}{$\begin{array}{c}\text { Cs } \\
\text { production }\end{array}$} \\
\hline & & & $\begin{array}{c}\text { content } \\
\text { (g/t U) }\end{array}$ & $\begin{array}{c}\text { error } \\
(\mathrm{g} / \mathrm{t} \mathrm{U})\end{array}$ & $\begin{array}{c}\text { rel } \\
\text { error } \\
(\%)\end{array}$ & $\begin{array}{c}\text { content } \\
(\mathrm{ppm} / \mathrm{t} \mathrm{U})\end{array}$ & $\begin{array}{c}\text { error } \\
(\mathbf{p p m} / \mathrm{t} \\
\mathrm{U})\end{array}$ & $\begin{array}{c}\text { rel } \\
\text { error } \\
(\%)\end{array}$ & $\begin{array}{c}\text { content } \\
\text { (g/t U) }\end{array}$ & $\begin{array}{c}\text { error } \\
\text { (g/t U) }\end{array}$ & $\begin{array}{c}\text { rel } \\
\text { error } \\
(\%)\end{array}$ & $\begin{array}{c}\text { content } \\
\text { (g/t U) }\end{array}$ & $\begin{array}{l}\text { error } \\
\text { (g/t U) }\end{array}$ & $\begin{array}{c}\text { rel } \\
\text { error } \\
(\%)\end{array}$ & $\begin{array}{l}\text { content } \\
\text { (at/t U) }\end{array}$ & $\begin{array}{c}\text { error } \\
\text { (at/t U) }\end{array}$ & $\begin{array}{c}\text { rel } \\
\text { error } \\
(\%)\end{array}$ \\
\hline 1 & 1079 & 11 & 239.5 & 63.7 & 26.6 & 56 & 14 & 25.0 & 3.37 & 0.19 & 5.6 & 463.9 & 18.4 & 4.0 & $9.04 \mathrm{E}+22$ & $3.50 \mathrm{E}+21$ & 3.9 \\
\hline 2 & 1079 & 12 & 386.5 & 27.6 & 7.1 & 67 & 6 & 9.0 & 1.36 & 0.08 & 5.9 & 343.7 & 12.2 & 3.5 & $6.39 \mathrm{E}+22$ & $2.50 \mathrm{E}+21$ & 3.9 \\
\hline 3 & 1079 & 17 & 425.5 & 27.6 & 6.5 & 60 & 14 & 23.3 & 3.00 & 0.17 & 5.7 & 386.1 & 13.7 & 3.5 & $7.26 \mathrm{E}+22$ & $2.80 \mathrm{E}+21$ & 3.9 \\
\hline 4 & 1079 & 18 & 468.1 & 27.6 & 5.9 & 78 & 11 & 14.1 & 1.77 & 0.10 & 5.6 & 396.9 & 14.0 & 3.5 & $7.67 \mathrm{E}+22$ & $3.00 \mathrm{E}+21$ & 3.9 \\
\hline 5 & 1179 & 10 & 613.3 & 36.6 & 6.0 & 122 & 7 & 5.7 & 2.69 & 0.15 & 5.6 & 658.3 & 23.3 & 3.5 & $1.32 \mathrm{E}+23$ & $5.20 \mathrm{E}+21$ & 3.9 \\
\hline 6 & 1179 & 11 & 652.3 & 36.6 & 5.6 & 110 & 14 & 12.7 & 5.22 & 0.29 & 5.6 & 677.3 & 23.9 & 3.5 & $1.35 E+23$ & $5.30 \mathrm{E}+21$ & 3.9 \\
\hline 7 & 1179 & 16 & 840.1 & 27.6 & 3.3 & 148 & 6 & 4.1 & 4.43 & 0.25 & 5.6 & 855.6 & 30.2 & 3.5 & $1.82 \mathrm{E}+23$ & $7.10 \mathrm{E}+21$ & 3.9 \\
\hline 8 & 1179 & 17 & 851.8 & 27.6 & 3.2 & 130 & 14 & 10.8 & 7.49 & 0.42 & 5.6 & 744.9 & 26.3 & 3.5 & $1.57 \mathrm{E}+23$ & $6.10 \mathrm{E}+21$ & 3.9 \\
\hline 9 & 1378 & 12 & 1713.7 & 36.6 & 2.1 & 290 & 14 & 4.8 & 15.90 & 0.89 & 5.6 & 1729.6 & 61.2 & 3.5 & $4.20 \mathrm{E}+23$ & $1.60 \mathrm{E}+22$ & 3.8 \\
\hline 10 & 1378 & 13 & 1792.6 & 36.6 & 2.0 & 314 & 14 & 4.5 & 10.16 & 0.57 & 5.6 & 1688.7 & 59.7 & 3.5 & $4.21 \mathrm{E}+23$ & $1.60 \mathrm{E}+22$ & 3.8 \\
\hline 11 & 582 & 10 & 577.0 & 36.6 & 6.3 & 106 & 7 & 6.6 & 2.58 & 0.14 & 5.4 & 566.2 & 20.0 & 3.5 & $1.09 \mathrm{E}+23$ & $4.30 \mathrm{E}+21$ & 3.9 \\
\hline 12 & 582 & 11 & 869.9 & 36.6 & 4.2 & 140 & 11 & 7.9 & 6.70 & 0.37 & 5.5 & 799.2 & 28.3 & 3.5 & $1.63 E+23$ & $6.40 \mathrm{E}+21$ & 3.9 \\
\hline 13 & 582 & 16 & 840.1 & 36.6 & 4.4 & 156 & 7 & 4.5 & 4.23 & 0.24 & 5.7 & 829.0 & 29.3 & 3.5 & $1.66 \mathrm{E}+23$ & $6.50 \mathrm{E}+21$ & 3.9 \\
\hline 14 & 582 & 17 & 752.1 & 36.6 & 4.9 & 120 & 11 & 9.2 & 5.71 & 0.32 & 5.6 & 708.6 & 25.1 & 3.5 & $1.40 \mathrm{E}+23$ & $5.50 \mathrm{E}+21$ & 3.9 \\
\hline 15 & 1078 & 12 & 1139.4 & 36.6 & 3.2 & 196 & 6 & 3.1 & 5.46 & 0.31 & 5.7 & 1170.1 & 41.0 & 3.5 & $2.54 \mathrm{E}+23$ & $9.90 \mathrm{E}+21$ & 3.9 \\
\hline 16 & 1078 & 13 & 1124.0 & 36.6 & 3.3 & 189 & 13 & 6.9 & 9.18 & 0.51 & 5.6 & 1018.8 & 36.0 & 3.5 & $2.17 E+23$ & $8.50 \mathrm{E}+21$ & 3.9 \\
\hline 17 & 3485 & 4 & 704.0 & 27.6 & 3.9 & 123 & 7 & 5.7 & 2.78 & 0.16 & 5.8 & 682.6 & 24.1 & 3.5 & $1.34 \mathrm{E}+23$ & $5.20 \mathrm{E}+21$ & 3.9 \\
\hline 18 & 3485 & 8 & 1284.6 & 27.6 & 2.1 & 224 & 10 & 4.5 & 5.54 & 0.31 & 5.6 & 1107.1 & 39.1 & 3.5 & $2.54 \mathrm{E}+23$ & $9.90 \mathrm{E}+21$ & 3.9 \\
\hline 19 & 3485 & 17 & 2055.7 & 27.6 & 1.3 & 356 & 9 & 2.5 & 9.78 & 0.55 & 5.6 & 1695.8 & 60.0 & 3.5 & $4.49 E+23$ & $1.80 \mathrm{E}+22$ & 4.0 \\
\hline $5^{* c}$ & 1179 & 10 & 731.2 & 36.6 & 5.0 & 124 & 7 & 5.6 & 2.82 & 0.16 & 5.7 & 575.4 & 20.3 & 3.5 & $1.19 E+23$ & $4.60 \mathrm{E}+21$ & 3.9 \\
\hline $6^{*}$ & 1179 & 11 & 715.8 & 36.6 & 5.1 & 110 & 14 & 12.7 & 7.12 & 0.40 & 5.6 & 585.7 & 20.7 & 3.5 & $1.20 \mathrm{E}+23$ & $4.70 \mathrm{E}+21$ & 3.9 \\
\hline
\end{tabular}

a Basis for reported production data is "grams per ton $U$ ", noted in the table as "g/t $U$ "

${ }^{b}$ Relative measurement error is calculated as the ratio (in \%) of the reported measurement error to corresponding measured content.
${ }^{c}$ Samples $5^{*}$ and $6^{*}$ are reported as duplicate measurements for samples 5 and 6 , respectively. 


\subsection{MEASUREMENT DATA REVIEW}

To enable a complete assessment of the experimental data, additional information on the measurements would likely reduce uncertainties in the benchmark specifications.

Additional information on the measurement dates is desirable in order to accurately simulate the correct decay time from discharge to the measurement date. The actinide results for ${ }^{241} \mathrm{Pu}$ are most affected.

It would also be valuable to obtain additional information on how the uncertainties were obtained, if they include only the mass spectrometry measurement errors or if they include other contributions, and to confirm the level of confidence in the uncertainty values. This information is relevant to the evaluation of the duplicate sets of measurement data reported for samples 5 and 6 .

Clarification of the Cs production measurements is needed to assess if the reported Cs atom concentrations include isotopes ${ }^{133} \mathrm{Cs},{ }^{134} \mathrm{Cs}$, ${ }^{135} \mathrm{Cs}$, and ${ }^{137} \mathrm{Cs}$, or only a subset of isotopes (e.g., gamma emitters ${ }^{137} \mathrm{Cs}$ and ${ }^{134} \mathrm{Cs}$ ). This may be confirmed with additional information on the measurement method used for Cs (mass spectrometry after separation, gamma spectrometry, etc.).

Clarification is also needed for the basis (ton $\mathrm{U}$ ) used to report the production data, to specify whether it refers to the mass of the fuel element that was dissolved for measurements, which includes uranium and aluminum, or to mass of uranium only in the fuel element. Note that the ratio of fuel element mass to uranium mass is $\sim 1.042$. In the current report, it was assumed that the basis (ton $\mathrm{U}$ ) refers to the uranium content in a measured fuel element.

The additional data needs for modeling and evaluation of experimental data are summarized in the Appendix.

\subsection{UNCERTAINTY EVALUATION}

Two sets of measurement data are reported for two samples selected from fuel elements 10 and 12 irradiated in process tube PT 1179 - samples identified as 5 and 6 in the PTA-069 test. Availability of duplicate measurement data is always beneficial for assessing the quality of the measurement data and the accuracy of the reported measurement uncertainties.

In addition, for this particular experiment, it may provide information on the variability of compositions within a fuel element, given that the measurement data are obtained from a very small 1/16 inch thick radial disc cut from the fuel element. However, it is not clear from the documentation when these samples were measured and if the replicate measurements were obtained from separate samples (cut at different locations) of the same fuel element or if these measurements were performed using the same sample solution (for the same radial disc cut from a fuel element). If the latter case were true (same sample solution), comparisons would provide relevant information on the repeatability of the measurements. If the former case were true (different sample cuts), the data for two different samples would provide insight into the variability within the fuel element and uncertainty contributions from cutting, fuel preparation, sample dissolution, and mass spectrometry measurements.

The reported measurement uncertainties for the uranium isotopic data for samples 5 and 6 are less than $1 \%$ for ${ }^{235} \mathrm{U}$ isotopic content; $2-4 \%$ for ${ }^{236} \mathrm{U}$; and $6-10 \%$ for ${ }^{234} \mathrm{U}$. The duplicate 
measurements for samples 5 and 6 agree within the reported uncertainties for all uranium isotopes.

The reported measurement uncertainties for the plutonium isotopic data for samples 5 and 6 are $\sim 0.03 \%$ for ${ }^{239} \mathrm{Pu} ;<0.5 \%$ for ${ }^{240} \mathrm{Pu}$; $\sim 2 \%$ for ${ }^{241} \mathrm{Pu} ; 10-13 \%$ for ${ }^{238} \mathrm{Pu}$; and $7-100 \%$ for ${ }^{242} \mathrm{Pu}$. The plutonium isotopic composition of sample 5 is $93.13 \%{ }^{239} \mathrm{Pu}, 6.340 \%{ }^{240} \mathrm{Pu}, 0.418 \%{ }^{241} \mathrm{Pu}$, $0.011 \%{ }^{242} \mathrm{Pu}$, and $0.010 \%{ }^{238} \mathrm{Pu}$. The duplicate measurement data for plutonium isotopic content in samples 5 and 6 , as seen in Table 7 , agree within $2 \sigma$ for all plutonium isotopes.

The measured production data for samples 5 and 6 have reported uncertainties of $5-6 \%$ for ${ }^{235} U$ depletion; 6-13\% for ${ }^{236} \mathrm{U}$ buildup; $6 \%$ for Np production; and 3.5\% for Pu production.

The Pu production values for the duplicate measurements are not within the reported measurement uncertainty (difference $14-16 \%$ ), as it can be noted from Table 9 . The same type of observation applies to the Cs production; there are differences in duplicate measured contents of $\sim 11-12 \%$, whereas reported measurement uncertainties are $\sim 6 \%$. The differences observed for $\mathrm{U}^{235}$ depletion for sample 5 (difference $\sim 16 \%$ ) and Np production in sample 6 (difference $\sim 27 \%$ ) are both larger than the reported measurement uncertainties.

For the purpose of comparing measured and calculated data, the duplicate measurement production data for samples 5 and 6 were combined by using as a weighting function the reported measurement uncertainty. The combination of the data was done [12] as shown in Eq. (3), where $x_{i}$ and $\sigma_{i}(\mathrm{i}=1,2)$ are, respectively, the reported measured values and reported corresponding uncertainties for the duplicate measurement for a given sample, and $\bar{x}$ and $\sigma$ are, respectively, the derived combined measured value and corresponding uncertainty.

$$
\bar{x}=\frac{\sum_{i=1}^{n} \frac{x_{i}}{\sigma_{i}^{2}}}{\sum_{i=1}^{n} \frac{1}{\sigma_{i}^{2}}} \text { and } \sigma^{2}=\frac{1}{\sum_{i=1}^{n} \frac{1}{\sigma_{i}^{2}}}
$$

For some of the samples, the reported uncertainties are the same irrespective of the sample exposure. For example, the reported uncertainty in ${ }^{235} \mathrm{U}$ depletion is “+/- $27.6 \mathrm{~g}{ }^{235} \mathrm{U} /$ ton $\mathrm{U}$ ” for all three samples (17 to 19) from PT 3485; whereas the reported measured ${ }^{235} \mathrm{U}$ depletion is in the range $704.0-2,055.7 \mathrm{~g}^{235} \mathrm{U} /$ ton $\mathrm{U}$ for the same samples. As it is expected that the uncertainty will vary with the sample exposure (or measured isotope content) similar to data for other samples, the reported uncertainty for these three particular samples may be erroneous. 
Table 9. Comparison of measurement production data for duplicate samples 5 and 6

\begin{tabular}{|c|c|c|c|c|c|c|c|c|c|c|c|c|}
\hline \multirow{2}{*}{$\begin{array}{l}\text { Sample } \\
\text { number }\end{array}$} & \multirow{2}{*}{$\begin{array}{c}\text { PT } \\
\text { number }\end{array}$} & \multirow{2}{*}{$\begin{array}{c}\text { Fuel } \\
\text { element }\end{array}$} & \multicolumn{2}{|c|}{${ }^{235} \mathrm{U}$ depletion } & \multicolumn{2}{|c|}{${ }^{236} \mathrm{U}$ buildup } & \multicolumn{2}{|c|}{ Np production } & \multicolumn{2}{|c|}{ Pu production } & \multicolumn{2}{|c|}{ Cs production } \\
\hline & & & g/ton U & error $^{a}(\%)$ & ppm/ton U & error (\%) & g/ton U & error (\%) & g/ton U & error (\%) & atoms/ton U & error $(\%)$ \\
\hline 5 & 1179 & 10 & 613.3 & 6.0 & 122 & 5.7 & 2.69 & 5.6 & 658.3 & 3.5 & $1.32 E+23$ & 3.9 \\
\hline $5^{*}$ & 1179 & 10 & 731.2 & 5.0 & 124 & 5.6 & 2.82 & 5.7 & 575.4 & 3.5 & $1.35 \mathrm{E}+23$ & 3.9 \\
\hline 6 & 1179 & 11 & 652.3 & 5.6 & 110 & 12.7 & 5.22 & 5.6 & 677.3 & 3.5 & $1.19 E+23$ & 3.9 \\
\hline $6 *$ & 1179 & 11 & 715.8 & 5.1 & 110 & 12.7 & 7.12 & 5.6 & 585.7 & 3.5 & $1.20 \mathrm{E}+23$ & 3.9 \\
\hline \multicolumn{13}{|l|}{ Ratios } \\
\hline \multirow{3}{*}{$\begin{array}{l}5 / 5^{*} \\
6 / 6^{*}\end{array}$} & & & ratio $^{b}$ & error $^{\mathrm{C}}$ & ratio & error & ratio & error & ratio & error & ratio & error \\
\hline & & & 0.839 & 0.065 & 0.984 & 0.079 & 0.954 & 0.076 & 1.144 & 0.057 & 1.109 & 0.061 \\
\hline & & & 0.911 & 0.069 & 1.000 & 0.180 & 0.733 & 0.058 & 1.156 & 0.058 & 1.125 & 0.062 \\
\hline \multicolumn{13}{|c|}{ Combined data } \\
\hline \multirow{3}{*}{$\begin{array}{l}5 \\
6\end{array}$} & & & $\mathrm{~g} /$ ton $\mathrm{U}$ & error $^{\mathrm{a}}(\%)$ & ppm/ton U & error (\%) & g/ton U & error (\%) & $\mathrm{g} /$ ton $\mathrm{U}$ & error (\%) & atoms/ton U & error (\%) \\
\hline & & & 672.3 & 3.8 & 123.0 & 4.0 & 2.75 & 4.0 & 611.2 & 2.5 & $1.25 \mathrm{E}+23$ & 2.8 \\
\hline & & & 684.1 & 3.8 & 110.0 & 9.0 & 5.87 & 4.0 & 625.0 & 2.5 & $1.27 \mathrm{E}+23$ & 2.8 \\
\hline
\end{tabular}

${ }^{\mathrm{a}}$ Relative measurement error is calculated as the ratio (in \%) of the reported measurement error to corresponding measured content.

${ }^{\mathrm{b}}$ Ratio of reported measured data for duplicate samples.

${ }^{\mathrm{c}}$ Error in ratio was calculated by error propagation based on the reported measurement error for the two duplicate sample measurements. 


\section{COMPUTATIONAL MODELS AND DATA}

Development of computational models for simulation of the Hanford B experiments requires detailed geometry information, material descriptions, and operating history data. These requirements apply even for a relatively simple configuration used for analysis of the Hanford B reactor measurements, as illustrated in Fig. 6. The model in this figure is a two-dimensional (2-D) representation of a fuel element and process tube in the surrounding graphite lattice. A reflective boundary condition was applied to the outer boundary of the graphite moderator block. This model is an adequate representation for cases where the PT contains only fuel elements of type O3N (see Fig. 3) and the nearest neighbor tubes are similar to the modeled PT. The interaction between different PTs in such cases is estimated to be minimal because of the large amount of graphite separating the tubes. However, the use of spacer elements, water mix elements, or the end region of the fuel elements, is not represented in the simplified model in Fig. 6. A more detailed three-dimensional (3-D) model would be necessary to include the heterogeneity within the PT. All simulation results presented in this report are based on the 2-D model shown in Fig. 6.

Simulations of the experiments were performed using version 6.1.2 of the SCALE nuclear analysis code system [13, 14] with ENDF/B-VII.0 nuclear cross section data [15]. The TRITON 2-D depletion sequence in SCALE [16] was used, which couples the NEWT 2-D discrete ordinates neutron transport code with the ORIGEN code [17] for burnup analysis and isotopic predictions. The NEWT neutron transport calculations were performed using the SCALE 238group cross section library based on ENDF/B-VII.0 data. The problem-dependent ENDF/B-VII.0 cross sections are collapsed using the transport flux solution in the fuel and are then used in the ORIGEN code to calculate the reaction rates and time-dependent nuclide compositions. ORIGEN also uses a special purpose activation library, containing reaction cross sections for 774 materials, which is based on the European JEFF-3.0/A library [18], to obtain cross sections for nuclides not available in ENDF/B-VII.0 (limited to 390 in the SCALE 238-group transport library). The nuclear decay data used in ORIGEN are based on the latest evaluations in ENDF/B-VII.1 [19].

The geometry data used for the model shown in Fig. 6 are consistent with data in Tables 1-2. The irradiation history and specific power data used in simulations are based on data presented in Tables $4-5$. In the present calculations, the time between discharge and the measurement date was assumed to be two months. 


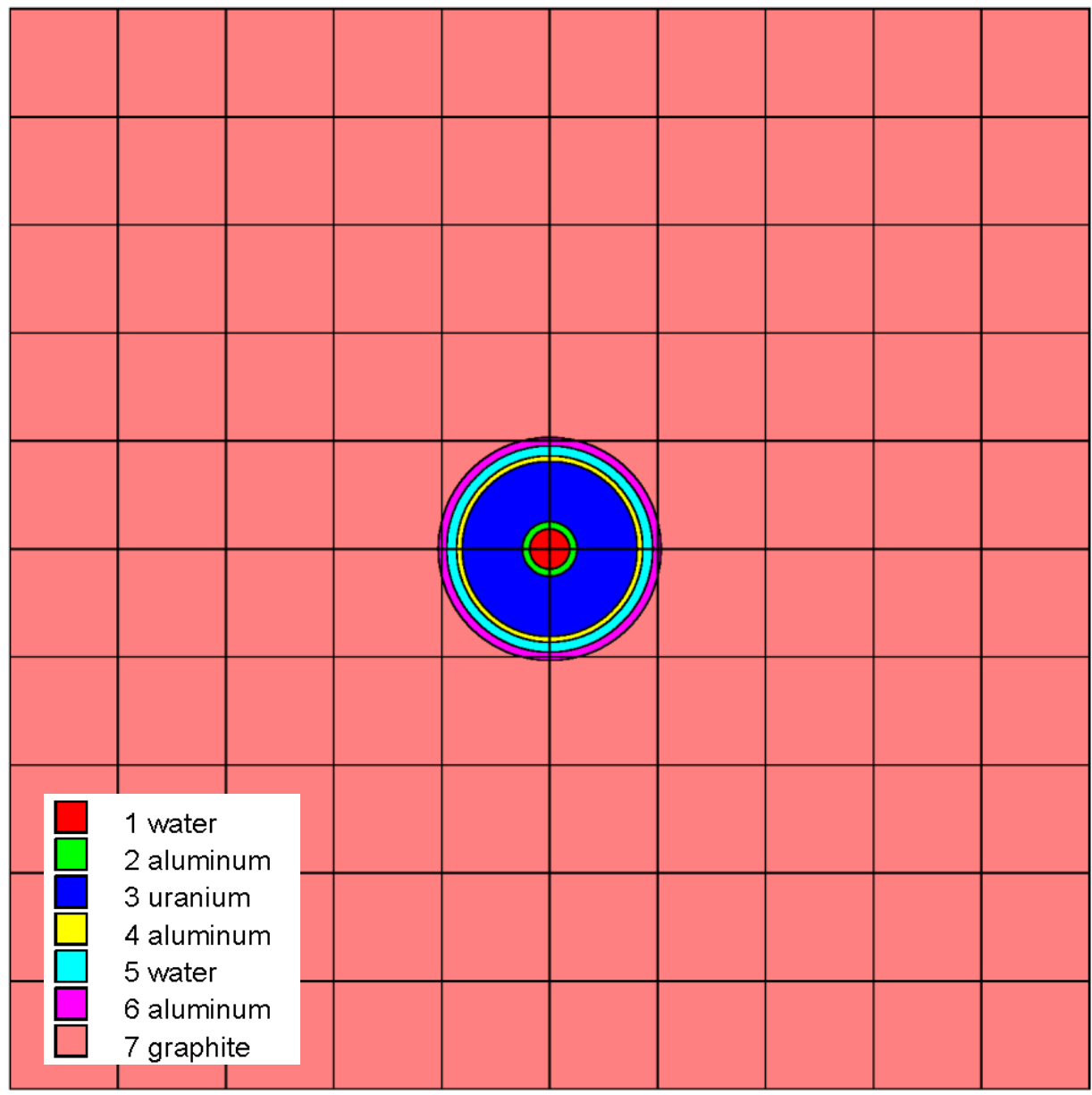

Fig. 6. Computational 2-D lattice model for Hanford B reactor process tube. 


\section{RESULTS FOR PTA-069 and PTA-084 EXPERIMENTS}

This section presents a comparison of the calculated isotopic and production contents that were obtained using the preliminary benchmark model description based on currently available Hanford B reactor data and the experimental data for the 19 fuel samples measured in the PTA069 and PTA-084 tests. The results discussed concern nuclides of highest importance to reactor analysis and actinide production: ${ }^{235} \mathrm{U}$ depletion and ${ }^{236} \mathrm{U}$ buildup; plutonium, neptunium, and cesium production; and isotopic distributions for uranium and plutonium.

The information presented here represents interim results based on the preliminary benchmark model. A quantitative assessment of the uncertainties in the benchmark information is not part of the current study but is being evaluated separately and will be documented as part of the final benchmark description.

The comparison of the calculated and measured data is quantified through a calculated-toexperimental ratio (C/E). The $\mathrm{C} / \mathrm{E}$ ratios are shown for each measured quantity and sample, along with the average $\mathrm{C} / \mathrm{E}$ over all samples and corresponding aggregate standard deviation. Note that the calculation of the standard deviation assumes that each sample is independent. However, samples obtained from the same production tube, will be subject to common uncertainties and biases that will correlate the observed deviations in some cases. Therefore the standard deviation values presented in this report are intended to provide a semi-quantitative measure of the scatter in the data.

\subsection{PRODUCTION DATA}

\subsubsection{U-235 Depletion}

The comparison of the calculated and measured data for ${ }^{235} \mathrm{U}$ depletion is illustrated in Figs. 7 and 8. Figure 7 shows the absolute values in $g{ }^{235} \mathrm{U} /$ ton $\mathrm{U}$ for the calculated and measured data as a function of exposure. Figure 8 presents the corresponding C/E. For samples 5 and 6 , the combined measurement data were used for comparison. Data for samples selected from the same tube are shown with the same color in Fig. 8. The error bars in the figures account only for the reported measurement uncertainties.

Samples from the same tube that have the same reported linear power (see Table 4) are expected to have similar measured data and C/E values. However, this is not the case at low values of the exposure, as observed for samples 1 and 2 from PT 1079 or samples 11 and 12 from PT 582. For higher exposure, the $\mathrm{C} / \mathrm{E}$ data for samples in the same tube and same reported linear power agree within the experimental uncertainty.

The agreement between calculation and experiment is within $20 \%$ for most of the samples. The average C/E over all 19 samples is 1.113, with a corresponding standard deviation of 0.170 $(15.2 \%)$.

\subsubsection{U-236 Buildup}

The comparison of the calculated and measured data for ${ }^{236} \mathrm{U}$ buildup is illustrated in Figs. 9 and 10. Figure 9 shows the absolute values in $g^{235} U /$ ton $U$ for the calculated and measured data as a function of exposure. The C/E agreement is better for ${ }^{236} \mathrm{U}$ buildup than for ${ }^{235} \mathrm{U}$ depletion at higher exposures. The average C/E over all 19 samples is 0.992 , with a corresponding standard deviation of $0.146(14.7 \%)$.

\subsubsection{Plutonium Production}

The comparison of the calculated and measured data for plutonium production is illustrated in Figs. 11 and 12. The predicted data are on average in reasonable agreement with the measured 
data, within $~ 5 \%$; the average $\mathrm{C} / \mathrm{E}$ over all samples is 0.948 , with a corresponding standard deviation of 0.151 (15.9\%). Note that the measurement uncertainty is 3.5-4\%. However, as observed from Figs. 11 and 12, there is a clear variation with burnup of the C/E data; production of plutonium is underestimated for lower burnups ( $<1000 \mathrm{MWd} / \mathrm{MTU})$, where there is considerable scatter in the data.

\subsubsection{Neptunium Production}

The comparison of the calculated and measured data for neptunium production is illustrated in Figs. 13 and 14. The average C/E over all samples is 0.879 , with a corresponding standard deviation of $0.213(24.2 \%)$. It is interesting to note that although, in general, there is some similarity in the C/E variation with burnup data for Np and Pu production (see Figs. 12 and 14), the underprediction of $\mathrm{Np}$ at lower burnups is more pronounced for the low burnup range, although, again there is considerable scatter in the data. Note that the production of neptunium (specifically ${ }^{237} \mathrm{~Np}$ ) depends on the initial ${ }^{236} \mathrm{U}$ content. This dependence is observed in Fig. 13, where the calculated and experimental data for the two initial ${ }^{236} \mathrm{U}$ contents in the measured samples $(0.0006 \%$ and $0.0410 \%)$ are shown in different colors.

\subsubsection{Cesium Production}

The cesium production measurements are reported as atoms/ton U. Based on the available reported data, it is not clear whether the measured amount of cesium refers to the total mass of all cesium isotopes or to the gamma emitters $\left({ }^{137} \mathrm{Cs}\right.$ and/or $\left.{ }^{134} \mathrm{Cs}\right)$ only. As indicated from the calculated data for cesium isotope contents at discharge in the considered samples, ${ }^{137} \mathrm{Cs}$ and ${ }^{133} \mathrm{Cs}$ (stable) are the main contributors to the total cesium mass, each with contributions of $43-49 \%$, depending on burnup; the contribution of ${ }^{135} \mathrm{Cs}$ is in the range of $5-10 \%$, whereas the ${ }^{134} \mathrm{Cs}$ content accounts for less than $1 \%$ of the cesium mass for all samples.

A comparison of the calculated and reported measurement data as a function of burnup confirmed that the measurements were likely based on gamma measurements of the ${ }^{137} \mathrm{Cs}$ content, since the calculated total cesium content was more than a factor of two larger (average $C / E=2.014$ ) than the reported measured data. The calculated results for ${ }^{137} \mathrm{Cs}$, as discussed in more detail in a further section of this report, are consistent with the measurements. 


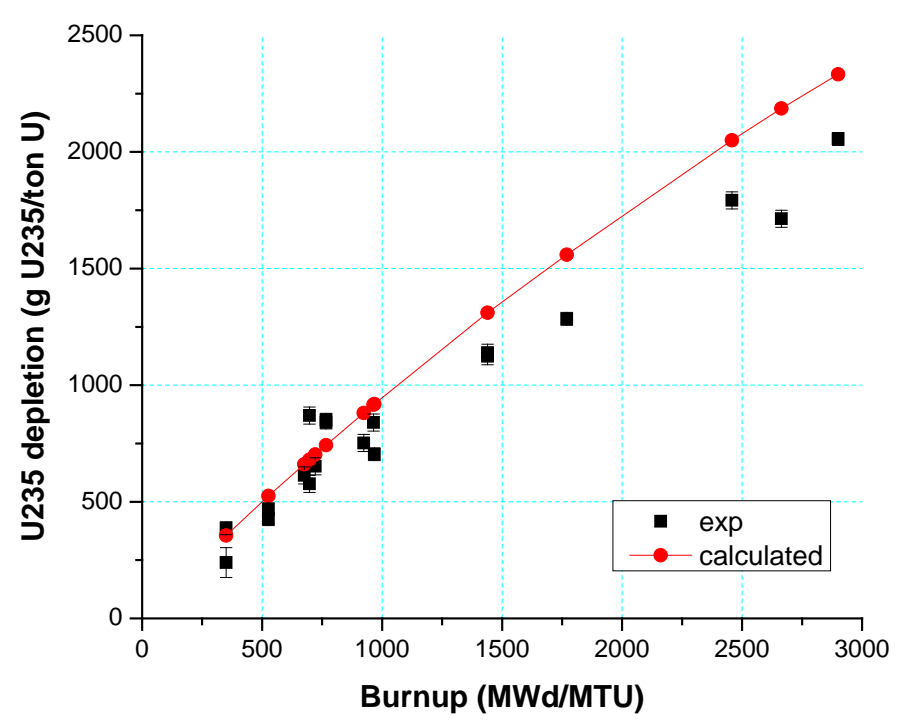

Fig. 7. Comparison of calculated and experimental data for ${ }^{235} \mathrm{U}$ depletion.

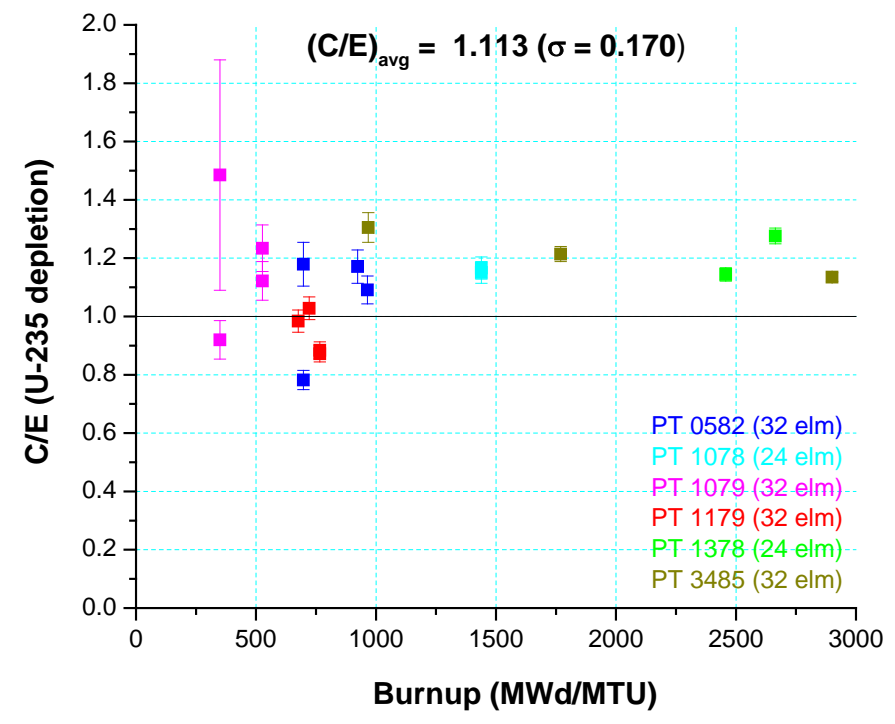

Fig. 8. Calculated-to-experimental ratio for ${ }^{235} \mathrm{U}$ depletion. 


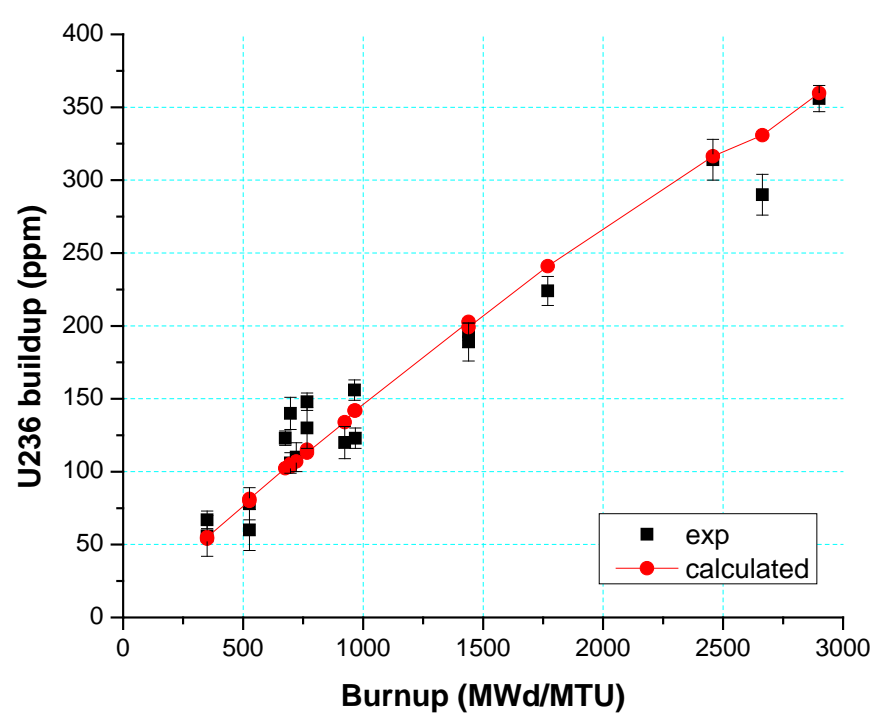

Fig. 9. Comparison of calculated and experimental data for ${ }^{236} \mathrm{U}$ buildup.

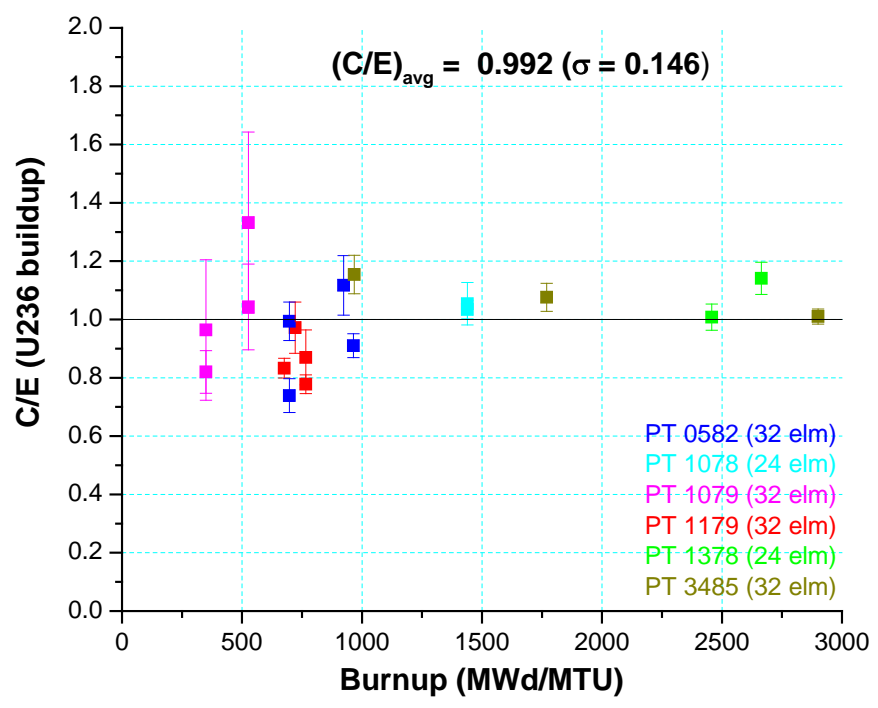

Fig. 10. Calculated-to-experimental ratio for ${ }^{236} \mathrm{U}$ buildup. 


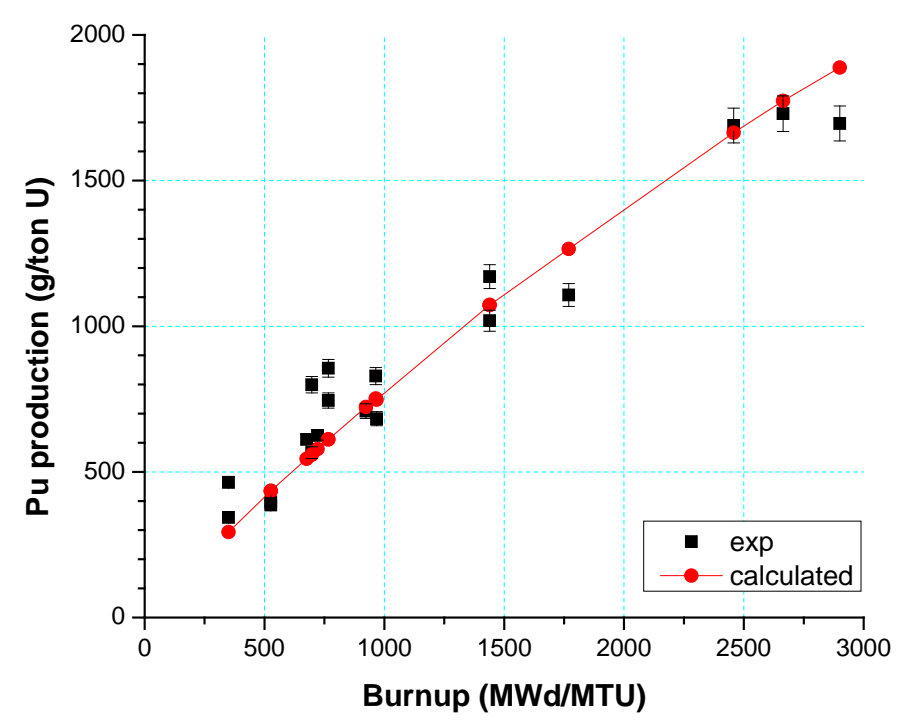

Fig. 11. Comparison of calculated and measured data for Pu production.

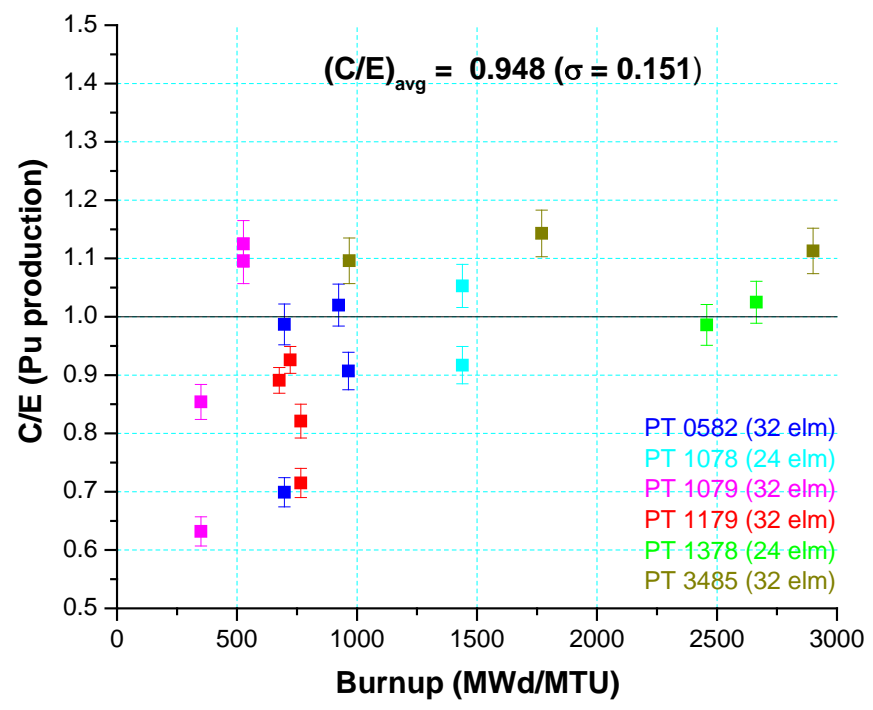

Fig. 12. Calculated-to-experimental ratio for Pu production. 


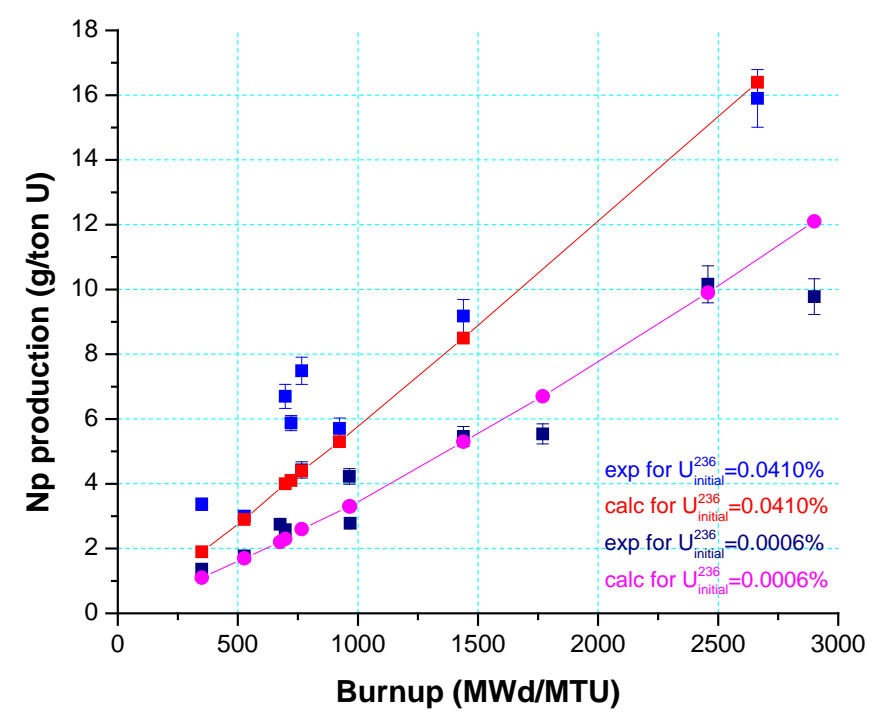

Fig. 13. Comparison of calculated and measured data for Np production.

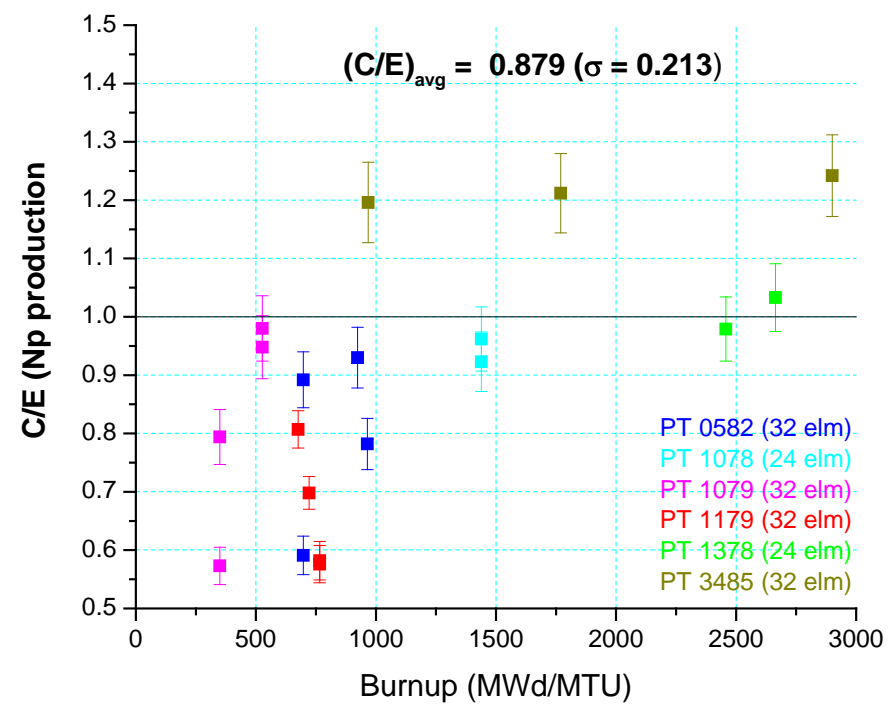

Fig. 14. Calculated-to-experimental ratio for Np production. 


\subsection{URANIUM AND PLUTONIUM ISOTOPIC CONTENT}

The comparison of the calculated and measured isotopic compositions for uranium and plutonium are presented in Table 10.

The isotopic content for ${ }^{235} U$ is well predicted on average, within $(1.9 \pm 3.1) \%$ of the measurement. A larger variation is seen for ${ }^{236} \mathrm{U}$, which is predicted on average within $(5.1 \pm 10.2) \%$ of the measured data. Note that most of uranium, more than $99 \mathrm{wt} \%$, in the initial or irradiated fuel, is ${ }^{238} \mathrm{U}$; there is a very small content of ${ }^{236} \mathrm{U}$ and ${ }^{234} \mathrm{U}$, in the range 0.007 to $0.070 \%$ and 0.005 to $0.007 \mathrm{wt} \%$, respectively, for irradiated fuel. The content of ${ }^{235} \mathrm{U}$ in total uranium is between 0.485 and $0.685 \mathrm{wt} \%$ for irradiated fuel, compared with $0.7119 \mathrm{wt} \%$ in initial fuel. The comparison of the calculated and measured data for ${ }^{235} U$ and ${ }^{236} U$ isotopic content is illustrated in Figs. 15-18. Figures 15 and 17 show the values in wt\% relative to the total U content for the calculated and measured data as a function of exposure. Figures 16 and 18 present the corresponding calculated-to-experimental ratios (C/E).

The ${ }^{239} \mathrm{Pu}$ isotopic content is consistently overestimated, whereas the ${ }^{240} \mathrm{Pu}$ content is consistently and significantly underestimated. On average, ${ }^{239} \mathrm{Pu}$ is predicted within $3.5 \pm 2.2 \%$ of the measurement, whereas ${ }^{240} \mathrm{Pu}$ is underpredicted by $38.3 \pm 11.1 \%$ compared with experiment. The underprediction of the ${ }^{241} \mathrm{Pu}$ and ${ }^{242} \mathrm{Pu}$ isotopic concentration, both produced by neutron capture of ${ }^{240} \mathrm{Pu}$, is observed to be even larger (38.9 and 57.3\%, respectively). The comparison of the calculated and measured data for ${ }^{239} \mathrm{Pu}$ and ${ }^{240} \mathrm{Pu}$ isotopic content is illustrated in Figs. 19-22. Figures 19 and 21 show the values in wt\% relative to the total Pu content for the calculated and measured data as a function of exposure. Figures 20 and 22 present the corresponding calculatedto-experimental ratios (C/E). Note that most of plutonium present in the samples (see Table 7) is

${ }^{239} \mathrm{Pu}$; therefore the large errors observed for ${ }^{240} \mathrm{Pu},{ }^{241} \mathrm{Pu}$, and ${ }^{242} \mathrm{Pu}$ do not dramatically impact the total plutonium production. A more detailed investigation into the potential cause of the large discrepancies in the plutonium isotopic content is presented in Section 7.2. 


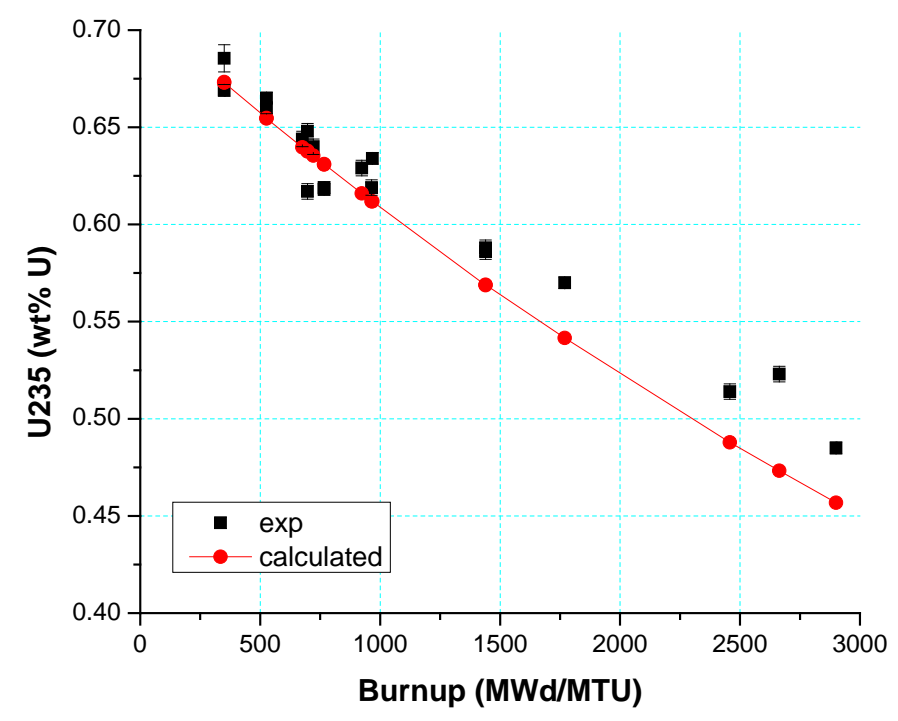

Fig. 15. Comparison of calculated and measured data for ${ }^{235} \mathrm{U}$ isotopic content.

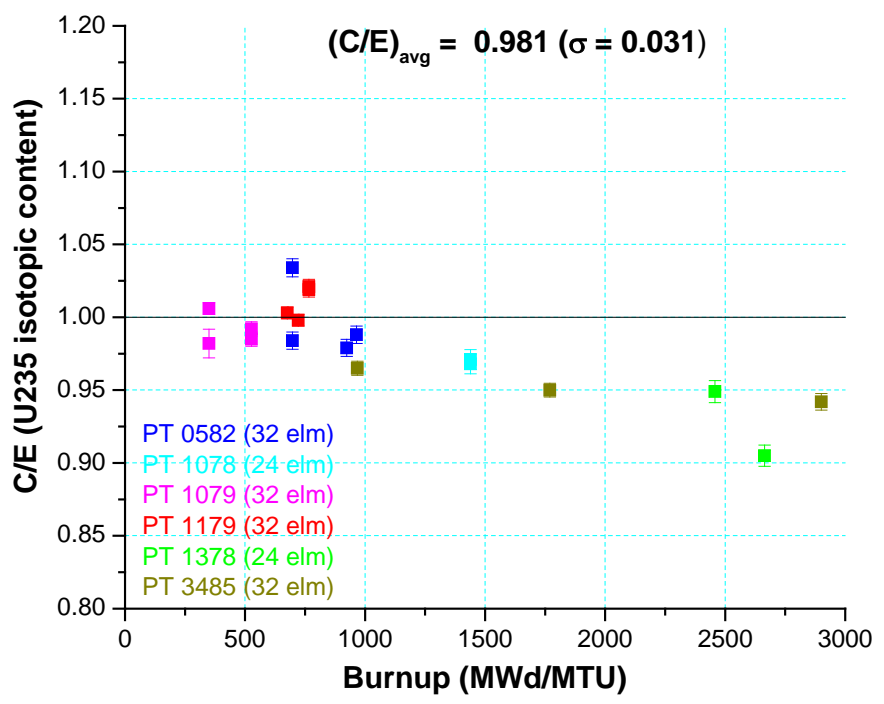

Fig. 16. Calculated-to-experimental ratio for ${ }^{235} \mathrm{U}$ isotopic content. 


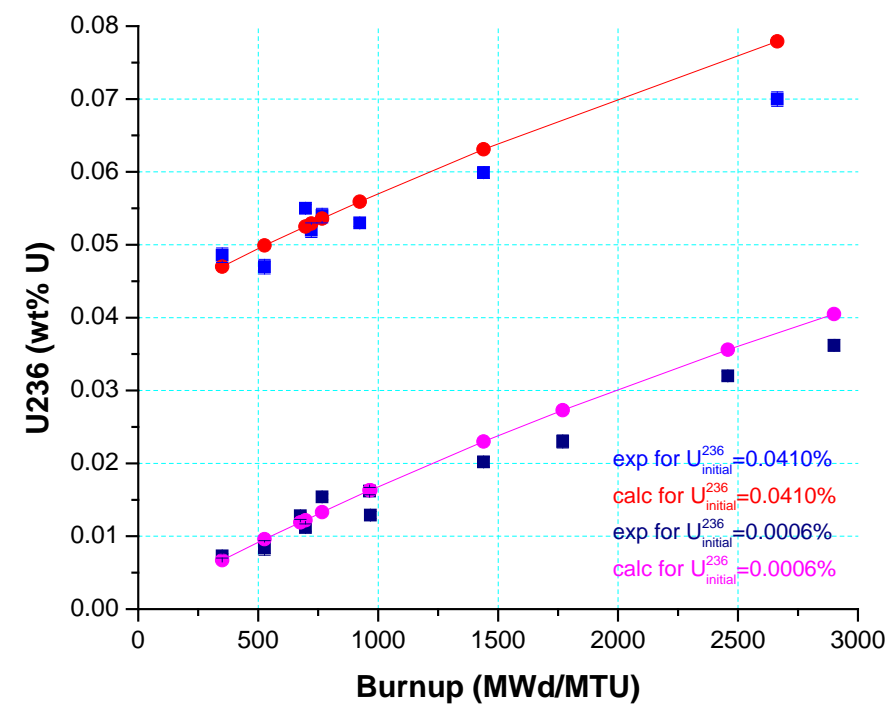

Fig. 17. Comparison of calculated and measured data for ${ }^{236} \mathrm{U}$ isotopic content.

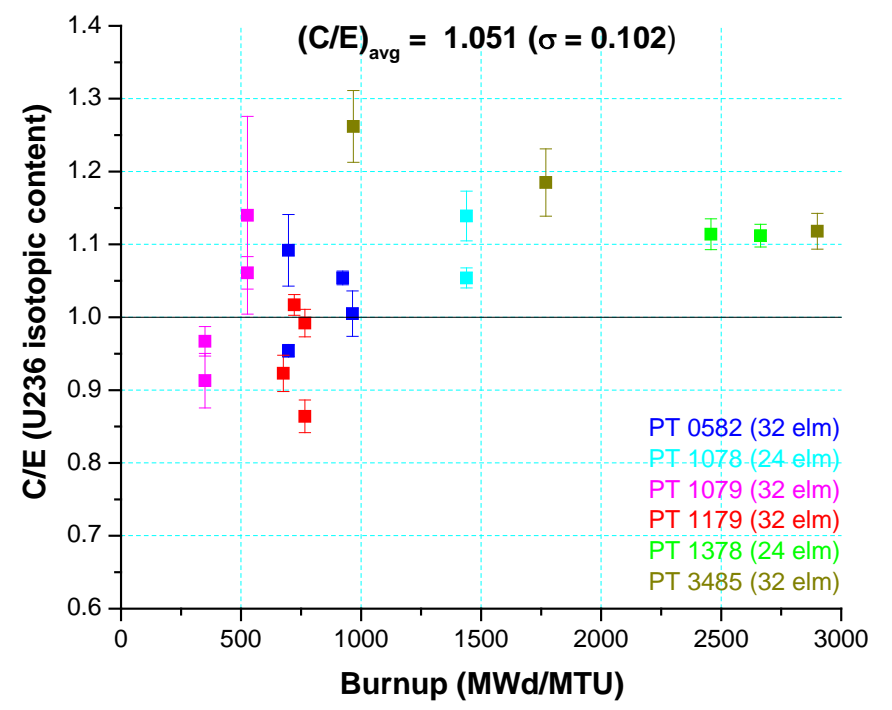

Fig. 18. Calculated-to-experimental ratio for ${ }^{236} \mathrm{U}$ isotopic content. 


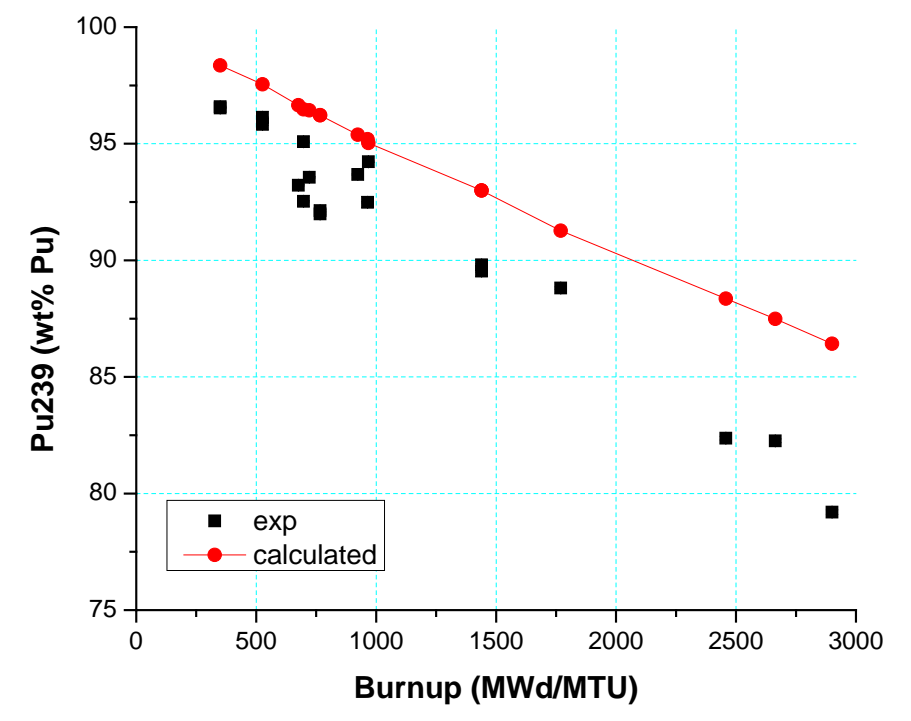

Fig. 19. Comparison of calculated and measured data for ${ }^{239} \mathrm{Pu}$ isotopic content.

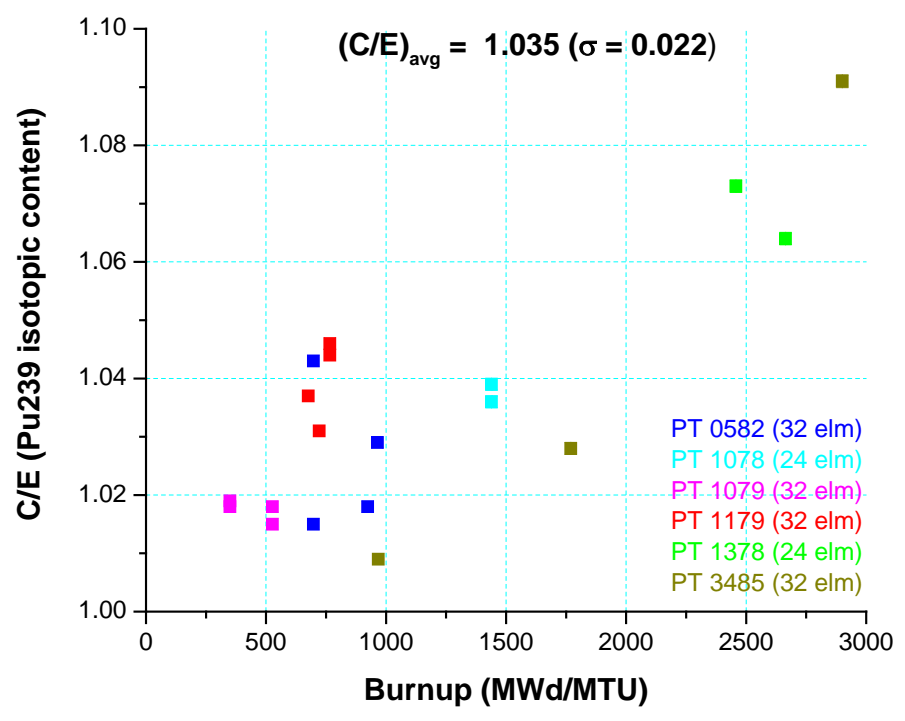

Fig. 20. Calculated-to-experimental ratio for ${ }^{239} \mathrm{Pu}$ isotopic content. 


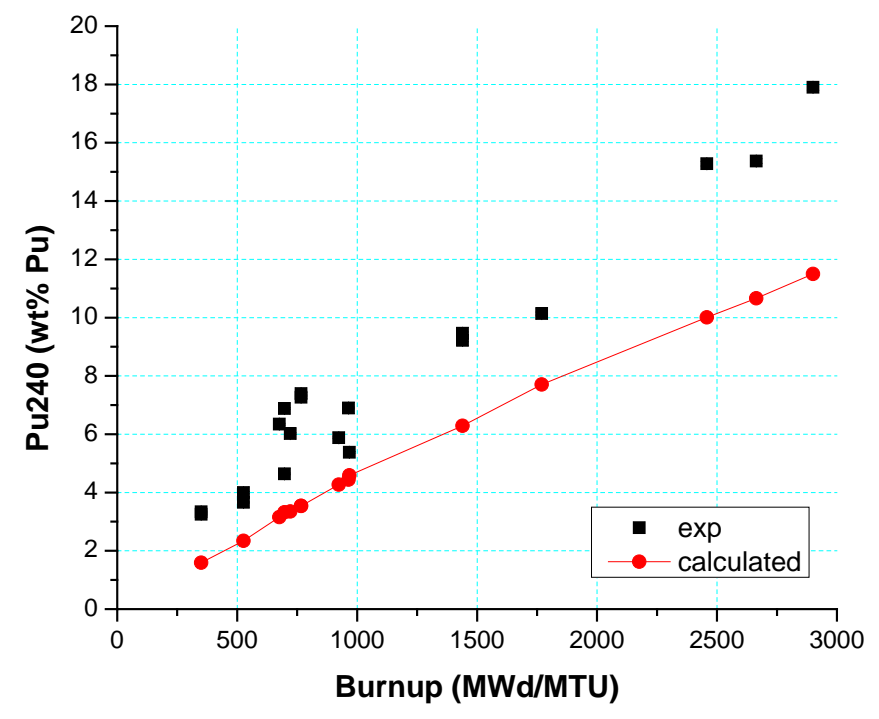

Fig. 21. Comparison of calculated and measured data for ${ }^{240} \mathrm{Pu}$ isotopic content.

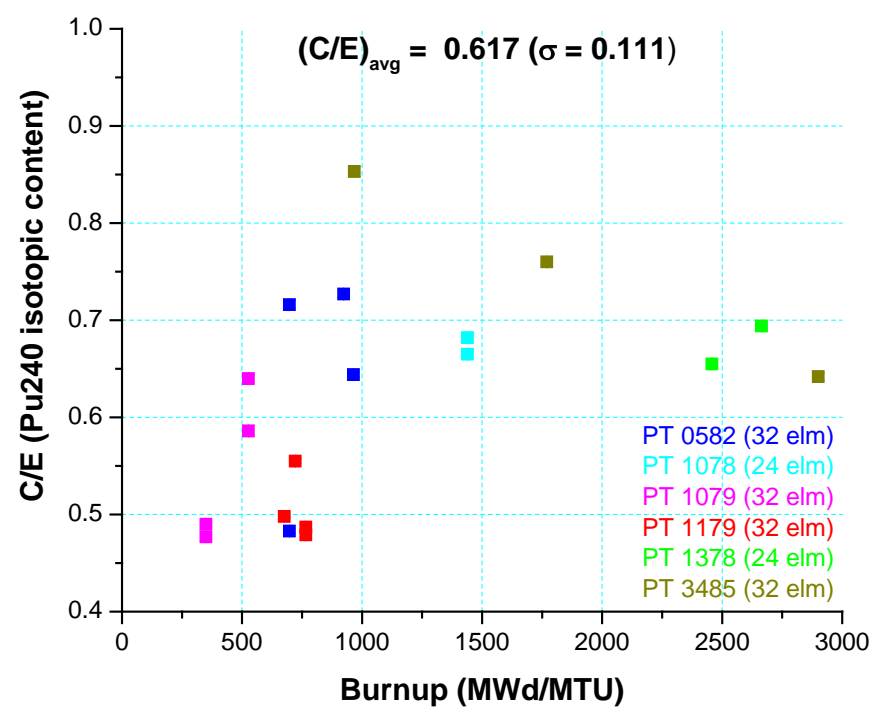

Fig. 22. Calculated-to-experimental ratio for ${ }^{240} \mathrm{Pu}$ isotopic content. 
Table 10. Comparison calculation-experiment for $\mathrm{U}$ and $\mathrm{Pu}$ isotopic composition

\begin{tabular}{|c|c|c|c|c|c|c|c|c|c|c|c|c|c|c|c|c|c|c|c|c|}
\hline \multirow{3}{*}{$\begin{array}{c}\text { Sample } \\
\text { No. }\end{array}$} & \multirow{3}{*}{$\begin{array}{l}\text { PT } \\
\text { No. }\end{array}$} & \multirow{3}{*}{$\begin{array}{c}\text { Burnup } \\
\text { (MWd/ } \\
\text { MTU) }\end{array}$} & \multicolumn{8}{|c|}{ Uranium isotopic content } & \multicolumn{10}{|c|}{ Plutonium isotopic content } \\
\hline & & & \multicolumn{2}{|c|}{ U-234 } & \multicolumn{2}{|c|}{ U-235 } & \multicolumn{2}{|c|}{ U-236 } & \multicolumn{2}{|c|}{ U-238 } & \multicolumn{2}{|c|}{ Pu-238 } & \multicolumn{2}{|c|}{ Pu-239 } & \multicolumn{2}{|c|}{ Pu-240 } & \multicolumn{2}{|c|}{ Pu-241 } & \multicolumn{2}{|c|}{ Pu-242 } \\
\hline & & & $\mathrm{C} / \mathrm{E}$ & $\begin{array}{c}\sigma^{\mathrm{a}} \\
(\%)\end{array}$ & $\mathrm{C} / \mathrm{E}$ & $\begin{array}{c}\sigma^{\mathrm{a}} \\
(\%)\end{array}$ & $\mathrm{C} / \mathrm{E}$ & $\begin{array}{c}\sigma^{\mathrm{a}} \\
(\%)\end{array}$ & $\mathrm{C} / \mathrm{E}$ & $\begin{array}{c}\sigma^{\mathrm{a}} \\
(\%)\end{array}$ & $\mathrm{C} / \mathrm{E}$ & $\begin{array}{c}\sigma^{\mathrm{a}} \\
(\%)\end{array}$ & $\mathrm{C} / \mathrm{E}$ & $\begin{array}{c}\sigma^{\mathrm{a}} \\
(\%)\end{array}$ & $\mathrm{C} / \mathrm{E}$ & $\begin{array}{c}\sigma^{\mathrm{a}} \\
(\%)\end{array}$ & $\mathrm{C} / \mathrm{E}$ & $\begin{array}{c}\sigma^{\mathrm{a}} \\
(\%)\end{array}$ & $\mathrm{C} / \mathrm{E}$ & $\begin{array}{c}\sigma^{\mathrm{a}} \\
(\%)\end{array}$ \\
\hline 1 & 1079 & 350.0 & 0.800 & 9.7 & 0.982 & 1.0 & 0.967 & 2.1 & 1.000 & $<0.01$ & 0.382 & 10.6 & 1.018 & $<0.1$ & 0.490 & 0.6 & 0.237 & 3.0 & 0.032 & 8.1 \\
\hline 2 & 1079 & 350.0 & 0.969 & 7.8 & 1.006 & 0.4 & 0.913 & 4.1 & 1.000 & $<0.01$ & 0.333 & 10.2 & 1.019 & $<0.1$ & 0.477 & 0.6 & 0.301 & 2.3 & $\mathrm{~N} / \mathrm{A}^{\mathrm{b}}$ & N/A \\
\hline 3 & 1079 & 526.7 & 0.792 & 8.1 & 0.985 & 0.5 & 1.061 & 2.1 & 1.000 & $<0.01$ & 0.812 & 10.4 & 1.015 & $<0.1$ & 0.640 & 0.6 & 0.540 & 3.7 & 0.264 & 200.0 \\
\hline 4 & 1079 & 526.7 & 0.963 & 7.8 & 0.992 & 0.5 & 1.140 & 11.9 & 1.000 & $<0.01$ & 0.702 & 9.3 & 1.018 & $<0.1$ & 0.586 & 1.0 & 0.503 & 5.2 & N/A & N/A \\
\hline 5 & 1179 & 676.0 & 0.914 & 4.0 & 1.003 & 0.4 & 0.923 & 2.7 & 1.000 & $<0.01$ & 1.061 & 14.6 & 1.037 & $<0.1$ & 0.498 & 0.5 & 0.361 & 1.4 & 0.260 & 61.5 \\
\hline 6 & 1179 & 721.7 & 0.702 & 7.1 & 0.998 & 0.4 & 1.017 & 1.4 & 1.000 & $<0.01$ & 1.308 & 16.0 & 1.031 & $<0.1$ & 0.555 & 0.5 & 0.421 & 1.4 & 0.313 & 8.7 \\
\hline 7 & 1179 & 766.2 & 0.920 & 9.4 & 1.019 & 0.5 & 0.864 & 2.6 & 1.000 & $<0.01$ & 0.492 & 10.0 & 1.044 & $<0.1$ & 0.487 & 0.6 & 0.328 & 1.7 & 0.225 & 10.5 \\
\hline 8 & 1179 & 766.2 & 0.799 & 9.8 & 1.021 & 0.5 & 0.992 & 1.9 & 1.000 & $<0.01$ & 0.522 & 10.0 & 1.046 & $<0.1$ & 0.479 & 0.5 & 0.322 & 1.7 & 0.203 & 19.0 \\
\hline 9 & 1378 & 2663.8 & 0.619 & 6.8 & 0.905 & 0.8 & 1.112 & 1.4 & 1.000 & $<0.01$ & 0.903 & 10.0 & 1.064 & $<0.1$ & 0.694 & 0.5 & 0.673 & 0.5 & 0.666 & 3.2 \\
\hline 10 & 1378 & 2457.5 & 0.870 & 11.3 & 0.949 & 0.8 & 1.114 & 1.9 & 1.000 & $<0.01$ & 0.858 & 10.0 & 1.073 & $<0.1$ & 0.655 & 0.5 & 0.606 & 0.5 & 0.542 & 3.2 \\
\hline 11 & 582 & 697.5 & 0.801 & 4.9 & 0.984 & 0.6 & 1.092 & 4.5 & 1.000 & $<0.01$ & 0.615 & 10.5 & 1.015 & $<0.1$ & 0.716 & 0.7 & 0.631 & 0.8 & 0.446 & 92.1 \\
\hline 12 & 582 & 697.5 & 0.788 & 4.8 & 1.034 & 0.6 & 0.954 & 0.9 & 1.000 & $<0.01$ & 0.546 & 10.0 & 1.043 & $<0.1$ & 0.483 & 0.4 & 0.288 & 0.5 & 0.169 & 5.0 \\
\hline 13 & 582 & 964.2 & 0.914 & 3.8 & 0.988 & 0.6 & 1.005 & 3.1 & 1.000 & $<0.01$ & 0.697 & 10.0 & 1.029 & $<0.1$ & 0.644 & 0.4 & 0.512 & 0.9 & 0.290 & 6.9 \\
\hline 14 & 582 & 923.2 & 0.758 & 4.7 & 0.979 & 0.6 & 1.054 & 0.9 & 1.000 & $<0.01$ & 0.929 & 10.0 & 1.018 & $<0.1$ & 0.727 & 0.5 & 0.636 & 0.9 & 0.414 & 6.9 \\
\hline 15 & 1078 & 1439.5 & 0.866 & 3.6 & 0.971 & 0.7 & 1.139 & 3.0 & 1.000 & $<0.01$ & 0.883 & 10.0 & 1.036 & $<0.1$ & 0.682 & 0.5 & 0.625 & 0.5 & 0.582 & 2.3 \\
\hline 16 & 1078 & 1439.5 & 0.769 & 3.2 & 0.968 & 0.7 & 1.054 & 1.3 & 1.000 & $<0.01$ & 0.830 & 10.0 & 1.039 & $<0.1$ & 0.665 & 0.5 & 0.606 & 0.5 & 0.568 & 2.3 \\
\hline 17 & 3485 & 967.9 & 0.968 & 10.0 & 0.965 & 0.5 & 1.262 & 3.9 & 1.000 & $<0.01$ & 1.153 & 0.6 & 1.009 & $<0.1$ & 0.853 & 0.6 & 0.823 & 0.5 & 0.978 & 5.5 \\
\hline 18 & 3485 & 1769.4 & 0.943 & 4.0 & 0.950 & 0.5 & 1.185 & 3.9 & 1.000 & $<0.01$ & 1.163 & 0.5 & 1.028 & $<0.1$ & 0.760 & 0.5 & 0.840 & 0.5 & 0.831 & 3.7 \\
\hline 19 & 3485 & 2900.2 & 0.909 & 6.0 & 0.942 & 0.6 & 1.118 & 2.2 & 1.000 & $<0.01$ & 0.851 & 0.6 & 1.091 & $<0.1$ & 0.642 & 0.6 & 0.752 & 0.8 & 0.483 & 0.9 \\
\hline & & Mean $^{c}$ & 0.845 & $11.6^{d}$ & 0.981 & 3.2 & 1.051 & 9.7 & 1.000 & $<0.01$ & 0.791 & 34.0 & 1.035 & 2.1 & 0.617 & 18.0 & 0.611 & 33.7 & 0.427 & 58.1 \\
\hline
\end{tabular}

Uncertainty refers only to the reported measurement uncertainty (see Tables $6-7$ ).

${ }^{6}$ Measured value and uncertainty for ${ }^{242} \mathrm{Pu}$ was reported as 0.0 for samples 2 and 4 .

${ }^{\mathrm{c}}$ Simple mean of C/E data.

${ }^{\mathrm{d}}$ Relative aggregate standard deviation for $\mathrm{C} / \mathrm{E}$ data. 


\section{DISCUSSION OF RESULTS FOR PTA-069 and PTA-084 EXPERIMENTS}

\subsection{EFFECT OF BURNUP UNCERTAINTY}

Although a thorough sensitivity and uncertainty analysis of the benchmark modeling parameters has not been addressed for this preliminary study, investigations have been performed to assess the potential impact of the burnup uncertainty on the uncertainty in the calculated responses (in this case, production data and uranium and plutonium isotopic compositions). In modern experimental programs, the burnup is usually determined experimentally using the measured content of ${ }^{148} \mathrm{Nd}$, a widely-used burnup indicator fission product, or based on measured data for other fission products that can be used as burnup indicators, such as combinations of neodymium isotopes or ${ }^{137} \mathrm{Cs}$ [12]. For the Hanford experiments, the cesium atom production was reported, and evaluations in this study strongly suggest this quantity is ${ }^{137} \mathrm{Cs}$, as discussed in Section 6.1.5. These Cs data therefore represent a potentially independent experimentally-based measure of the fuel burnup.

The variation with the nominal burnup of the measurement data for cesium, illustrated in Fig. 23, indicates a near-linear behavior; the scatter of the individual points around the fitted line are indicative of differences between the cesium-based sample burnup and the nominal burnup based on the reported operational history. The comparison of the calculated ${ }^{137} \mathrm{Cs}$ and the reported measured data for cesium shows an average C/E of 0.904, but a large scatter of the individual points around the mean value, especially for the very low burnup range.

To assess the effect of potential uncertainty in burnup as indicated by Fig. 23, the reported burnup (Table 6) was normalized to the measured cesium content, as shown in Eq. (4); in this equation, B stands for burnup, $i$ identifies the sample, and indices 0 and 1 refer to the data calculated using the original nominal burnup for each sample and the Cs-adjusted burnup, respectively. The burnup adjustment would ensure a C/E value of 1.

$$
B_{1}^{i}=\frac{B_{0}^{i}}{(C / E)_{0}^{i}} \quad i=1, \ldots, 19
$$

The depletion simulations were redone using the same benchmark model described previously in this report, but with the newly-determined burnup (and corresponding specific power).

The production results as obtained using the two burnup datasets (one nominal, based on operating data, and the other normalized to the measured cesium content) are summarized in Table 11, which shows the average C/E over all 19 samples and the corresponding standard deviation for ${ }^{235} \mathrm{U}$ depletion, ${ }^{236} \mathrm{U}$ buildup, Pu production, and Np production. The results obtained with the two burnup datasets for $\mathrm{U}$ and $\mathrm{Pu}$ isotopic compositions are summarized in Table 12. The comparison of the new calculated data and measured production data is presented in Figs. 2427.

As noted from Table 11, the average C/E values for the production data obtained with the Csbased burnup agree within the standard deviation with the values obtained using the nominal burnup.

The average C/E and corresponding standard deviation for ${ }^{235} \mathrm{U}$ depletion increases using cesium -based burnup. However, this increase is mostly due, as illustrated in Fig. 24, by the contribution of an outlier data point. The very large measurement uncertainty (26\%) relative to all other samples (2-7\%) indicates there were recognized experimental problems, supporting possible 
rejection of this measurement. This problem appears to be isolated to the uranium data. If this measurement were removed from the calculation of the average, the $\mathrm{C} / \mathrm{E}$ mean and standard deviation would decrease to 1.180 and 0.070 , respectively, and would be therefore much closer to the corresponding values obtained with the nominal burnup. However, in the current analysis all data have been retained, pending further uncertainty analysis. A similar decrease would be observed for the ${ }^{236} \mathrm{U}$ buildup data if the point with the largest C/E value (see Fig. 25) would not be considered in the calculation of the mean value. Note that the largest $\mathrm{C} / \mathrm{E}$ values for both ${ }^{235} \mathrm{U}$ depletion and ${ }^{236} U$ buildup correspond to the same sample, as seen in Figs. 24-25, and are associated with very large measurement uncertainties.

The plutonium and neptunium production results are clearly improved using cesium-based burnup (compare Figs. 26 and 27 with Figs. 12 and 14, respectively). In the case of the plutonium production, the relative standard deviation decreases from $\sim 16 \%$ to less than $3 \%$ (see Table 11). The relative standard deviation for the neptunium production data is reduced to approximately half of its initial value. On average, the plutonium production is overestimated by $\sim 4 \%$ using cesium-based burnup, compared to an underestimation by 5\% when using the nominal burnup. The neptunium production is on average underestimated for both burnup datasets, though with the cesium-based burnup the average underprediction is only 3\%.

There is not much impact of the burnup change on the calculated uranium and plutonium isotopic composition. This is expected, as the isotopic compositions would not be significantly affected by small changes in the burnup. It clearly indicates that the significant underestimation of the ${ }^{240} \mathrm{Pu}$ content is not caused by an uncertainty in the burnup. A more detailed discussion of the potential causes for this underestimation is provided in Section 7.2 of this report.

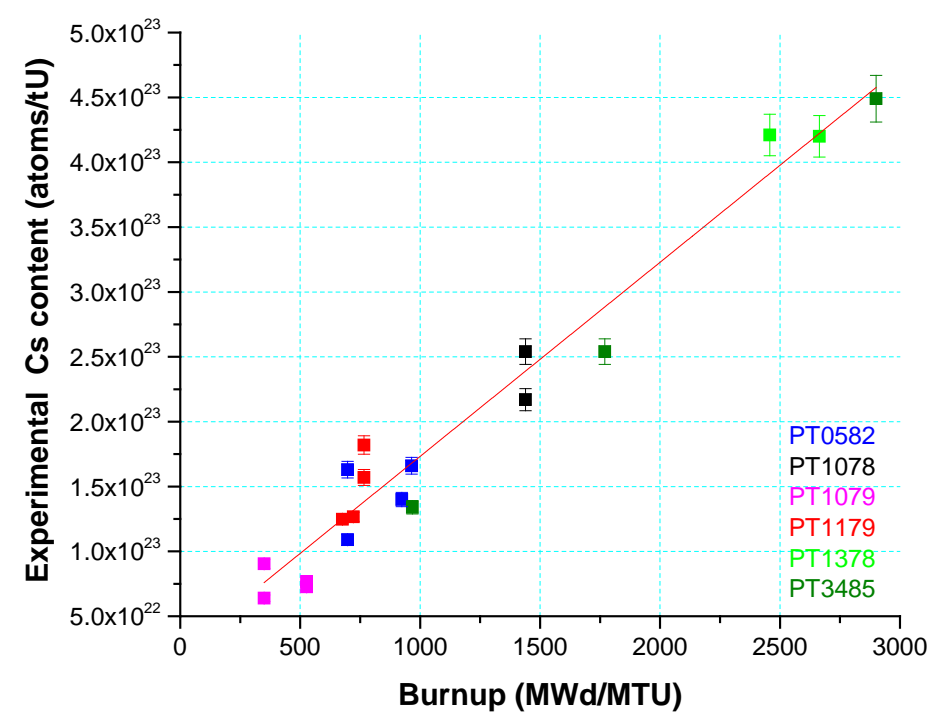

Fig. 23. Variation with nominal burnup of the measured data for cesium. 
Table 11. Effect of burnup on production data prediction

\begin{tabular}{|l|c|c|c|c|}
\hline \multirow{2}{*}{ Measured quantity } & \multicolumn{2}{|l|}{ Nominal burnup } & \multicolumn{2}{l|}{ Cs-based burnup } \\
\cline { 2 - 5 } & $(\mathrm{C} / \mathrm{E})_{\text {avg }}$ & $\sigma$ & $(\mathrm{C} / \mathrm{E})_{\text {avg }}$ & $\sigma$ \\
\hline & & & & \\
U-235 depletion & 1.113 & 0.170 & 1.247 & 0.298 \\
U-236 buildup & 0.992 & 0.146 & 1.100 & 0.138 \\
Pu production & 0.948 & 0.151 & 1.041 & 0.029 \\
Np production & 0.879 & 0.213 & 0.974 & 0.117 \\
& & & & \\
\hline
\end{tabular}

Table 12. Effect of burnup on predicted $U$ and Pu isotopic composition

\begin{tabular}{|c|c|c|c|c|}
\hline \multirow{2}{*}{ Isotope } & \multicolumn{2}{|c|}{ Nominal burnup } & \multicolumn{2}{c|}{ Cs-based burnup } \\
\cline { 2 - 5 } & $(\mathrm{C} / \mathrm{E})_{\text {avg }}$ & $\sigma$ & $(\mathrm{C} / \mathrm{E})_{\text {avg }}$ & $\sigma$ \\
\hline & & & & \\
U-234 & 0.845 & 0.098 & 0.843 & 0.098 \\
U-235 & 0.981 & 0.031 & 0.966 & 0.027 \\
U-236 & 1.051 & 0.102 & 1.110 & 0.072 \\
U-238 & 1.000 & 0.000 & 1.000 & 0.000 \\
& & & & \\
Pu-238 & 0.791 & 0.269 & 0.876 & 0.250 \\
Pu-239 & 1.035 & 0.022 & 1.030 & 0.021 \\
Pu-240 & 0.617 & 0.111 & 0.679 & 0.073 \\
Pu-241 & 0.611 & 0.206 & 0.716 & 0.115 \\
Pu-242 & 0.427 & 0.248 & 0.527 & 0.191 \\
& & & & \\
\hline
\end{tabular}




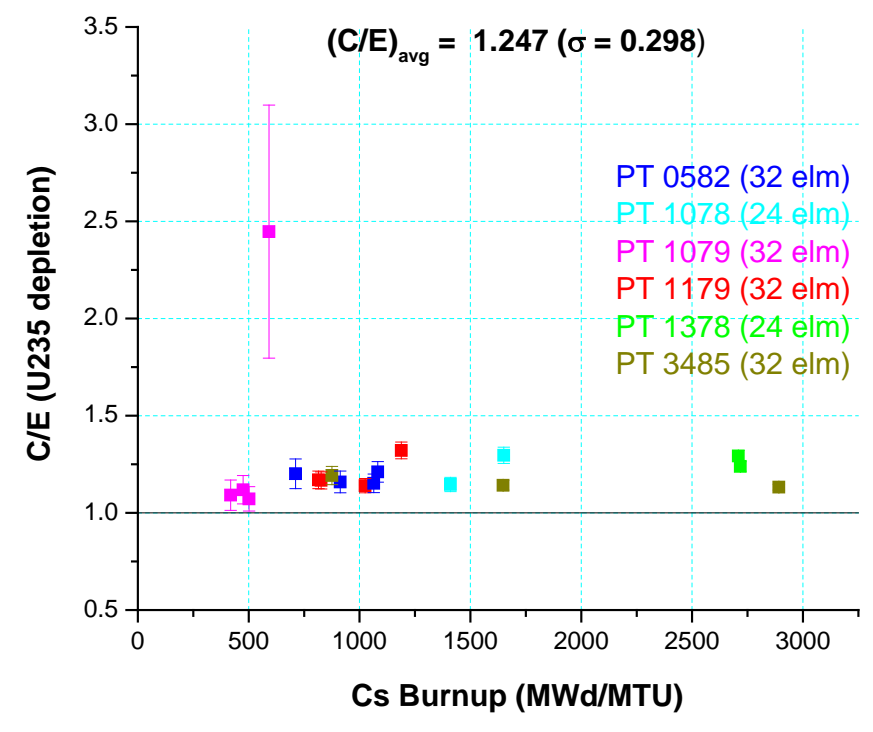

Fig. 24. Comparison of calculated and experimental data for ${ }^{235} \mathrm{U}$ depletion (Cs burnup).

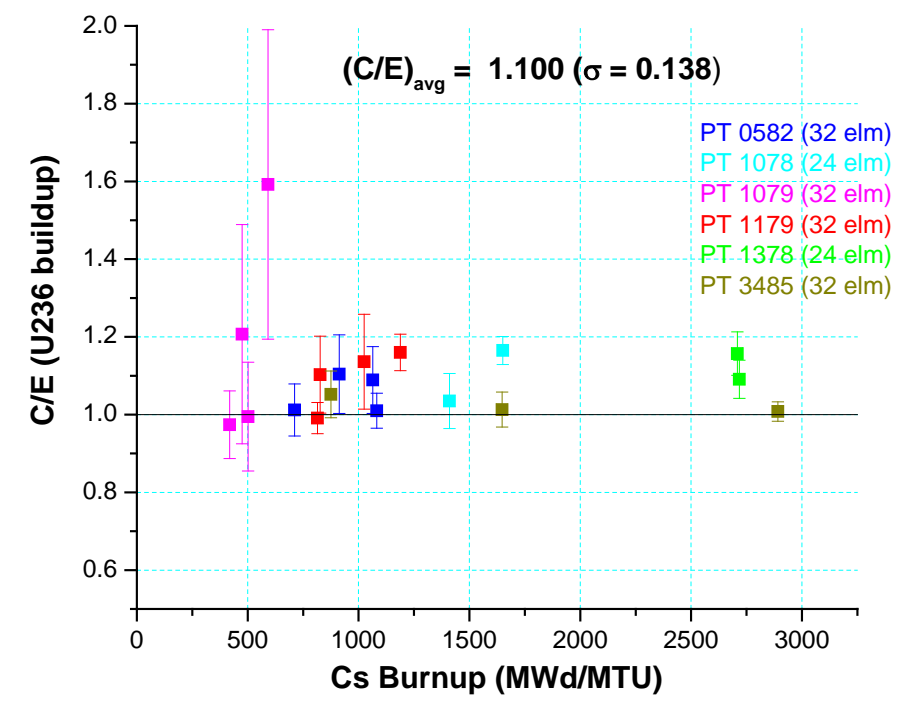

Fig. 25. Comparison of calculated and experimental data for ${ }^{236} \mathrm{U}$ buildup (Cs burnup). 


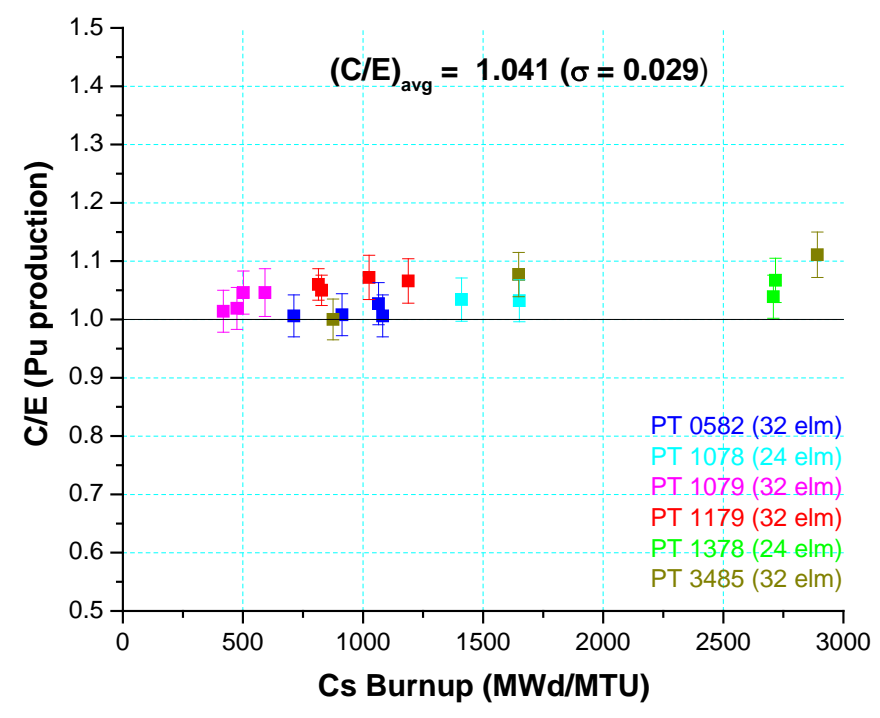

Fig. 26. Comparison of calculated and experimental data for Pu production (Cs burnup).

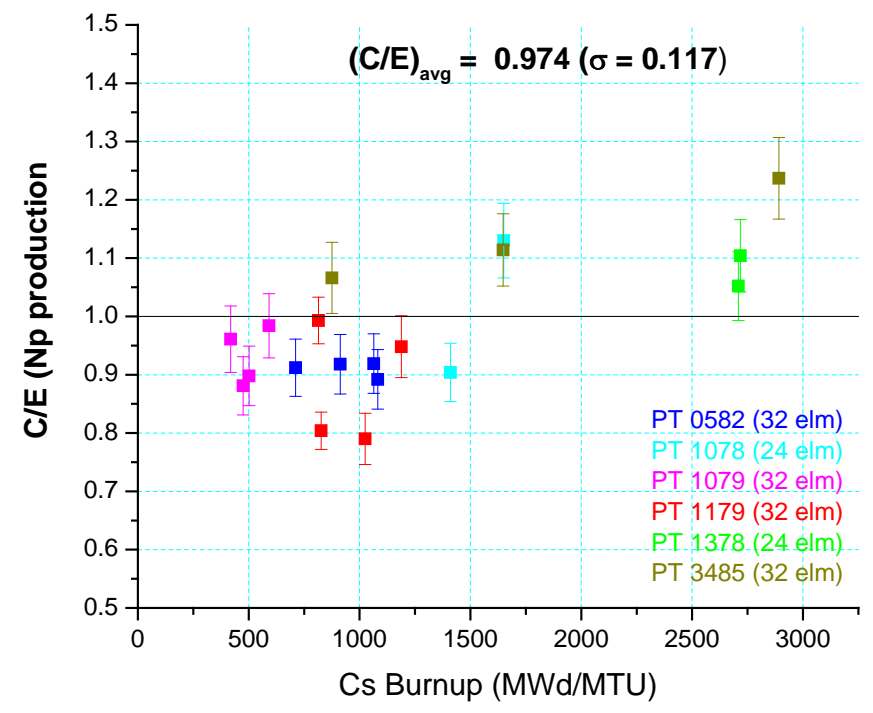

Fig. 27. Comparison of calculated and experimental data for Np production (Cs burnup). 


\subsection{EVALUATION OF NUCLEAR DATA}

The isotopic concentration for ${ }^{240} \mathrm{Pu}$, the second largest plutonium isotopic component for the analyzed samples, varies in the range of $\sim 3-9 \mathrm{wt} \%$ for most of the measured samples, except for very high exposure samples 9,10 , and 19 ( 15-18 wt\%). In light of the relative high accuracy of the mass spectrometry measurements, the severity of the underestimation of ${ }^{240} \mathrm{Pu}$ (and also ${ }^{241} \mathrm{Pu}$ and ${ }^{242} \mathrm{Pu}$ ) indicates that the production of ${ }^{240} \mathrm{Pu}$ is not being adequately simulated. This finding is unexpected, since benchmarking experience using measured plutonium from more than 90 different spent fuel samples from commercial light water reactors suggests that ${ }^{240} \mathrm{Pu}$ is very well calculated, with a bias of $2 \%$ and associated relative standard deviation of 3.2\% [20]. In addition, studies involving graphite gas cooled MAGNOX reactors [8] and graphite-moderated and lightwater-cooled RBMK reactors [21, 22], show a good agreement between calculations and measurements, indicating that there are no fundamental issues related to modeling graphitemoderated systems.

The unique nature of the Hanford B reactor experiments is the very low burnup range of the measurements, 300 to 2,900 MWd/MTU, compared with the Magnox fuel (3,900 to 9,400 MWd/MTU) or RBMK fuel (6,000 to 23,000 MWd/MTU) data. Additional studies were undertaken to investigate the plutonium production routes at very low burnup.

The main route for production of ${ }^{240} \mathrm{Pu}$ from low enriched uranium for commercial fuel exposures is ${ }^{238} \mathrm{U} \rightarrow{ }^{239} \mathrm{U} \rightarrow{ }^{239} \mathrm{~Np} \rightarrow{ }^{239} \mathrm{Pu} \rightarrow{ }^{240} \mathrm{Pu}$ (see Fig. 28). Neutron capture by ${ }^{239} \mathrm{~Np}$ is typically not important because of its relatively short 2.3 day half-life.

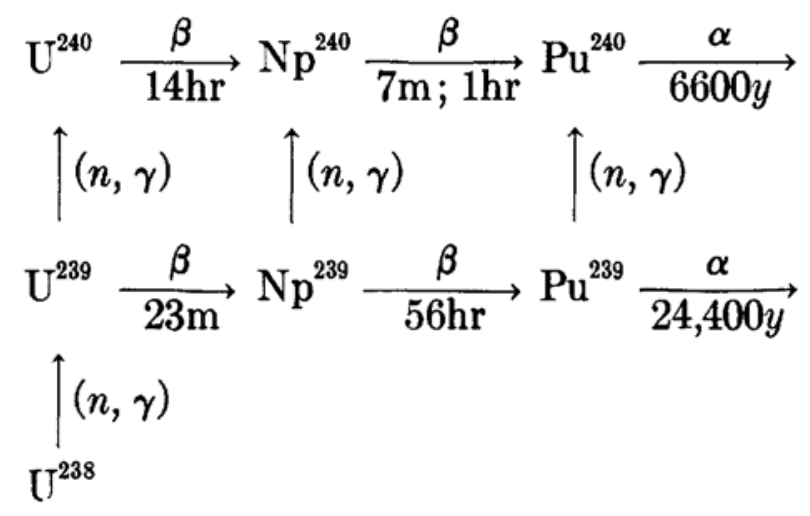

Fig. 28. Main routes [23] for plutonium production from ${ }^{238} U$.

At very low exposures consistent with the burnup of the Hanford experiments, transmutation studies performed using ORIGEN [17] found that that production of ${ }^{240} \mathrm{Pu}$ via ${ }^{239} \mathrm{~Np}$ capture is an important path [24]. However, the importance of ${ }^{239} \mathrm{~Np}$ capture to ${ }^{240} \mathrm{Pu}$ production decreases with increasing burnup and the effect is not observed for burnups of typical commercial fuel [20]. This production path was also recognized in early studies performed circa 1956 [23], which were the basis of measurements of the ${ }^{239} \mathrm{~Np}$ capture cross section in 1956 and 1959. These early measurements still form the basis for the cross-section data used in the US Evaluated Nuclear Data Files ENDF/B-VII.0. The large discrepancies observed for ${ }^{240} \mathrm{Pu}$ and higher mass plutonium isotopes suggest that the ${ }^{239} \mathrm{~Np}$ neutron capture cross section is significantly too low. 
A preliminary analysis of the ${ }^{239} \mathrm{~Np}$ neutron capture cross sections found large differences between the evaluations in ENDF/B-VII.0 and European Activation File (EAF-2003) cross sections, and also between evaluations in ENDF/B-VII.1 and TENDL (TALYS-based Evaluated Nuclear Data Library) nuclear data library [25] that provides the output of the TALYS nuclear model code system for direct use in both basic physics and applications. These different cross section evaluations are illustrated in Fig. 29. The recommended [26] thermal cross-section (labeled ATLAS 2006 in Fig. 29) is also shown.

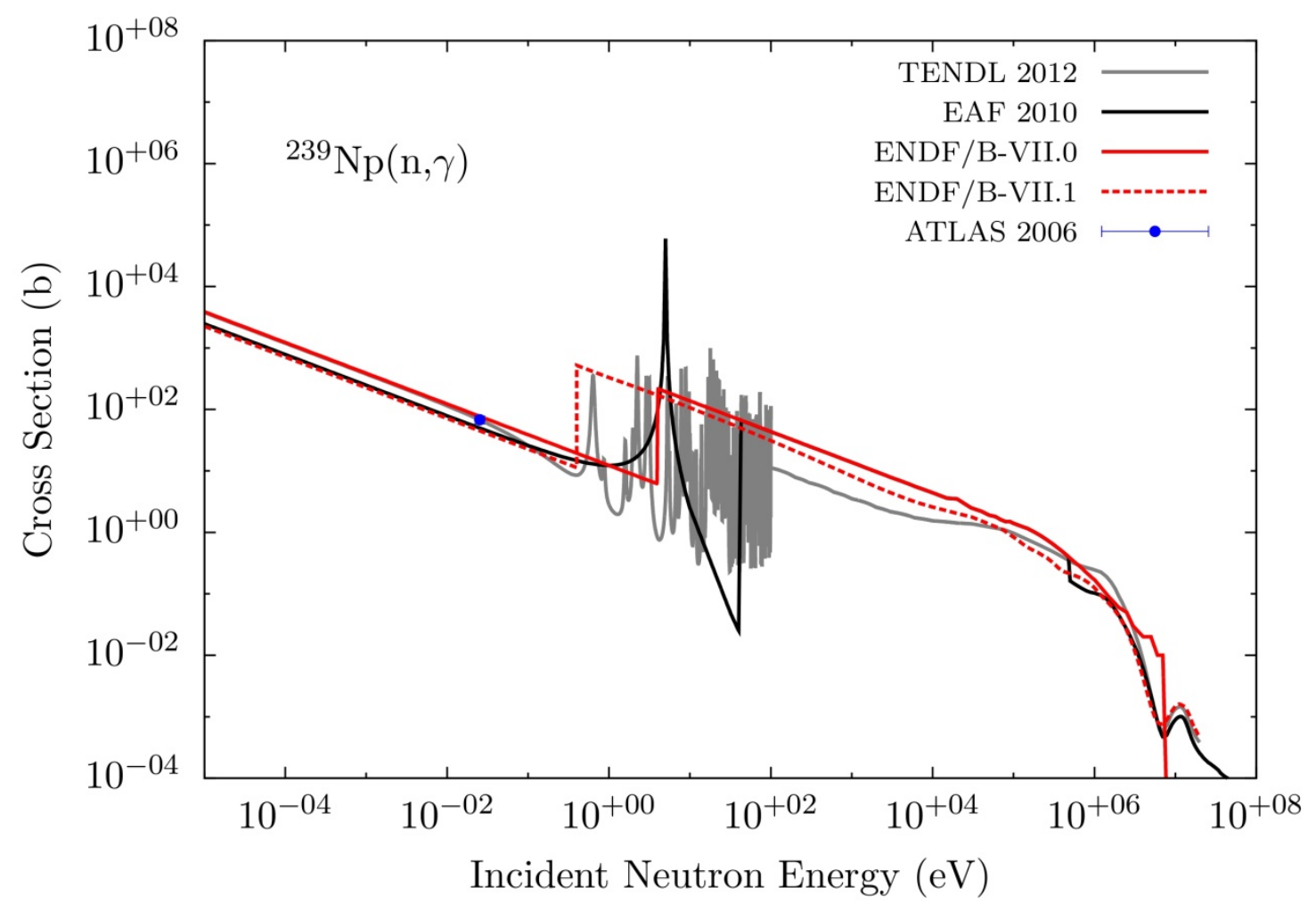

Fig. 29. Comparison of ${ }^{239} \mathrm{~Np}$ capture cross section evaluations.

The effective, problem-dependent cross section is obtained by weighting the energy-dependent cross section in Fig. 29 using the spectrum in the Hanford B reactor fuel to obtain the total effective cross-section value. The effective cross sections corresponding to the different evaluations are summarized in Table 13 for one of the samples. There is approximately a factor of two difference between the smallest cross section (ENDF/B-VII.0) and the largest (EAF-2003). 
Table 13. Effective ${ }^{239} \mathrm{~Np}$ capture cross section

\begin{tabular}{|l|c|}
\hline Library & $\begin{array}{c}\text { Capture cross section } \\
\text { (b) } *\end{array}$ \\
\hline ENDF/B-VII.0 & 28.0 \\
ENDF/B-VII.1 & 35.2 \\
EAF -2003 & 49.0 \\
TENDL & 28.7 \\
\hline
\end{tabular}

For the Hanford samples considered in this report, ORIGEN calculations performed using EAF$2003{ }^{239} \mathrm{~Np}(\mathrm{n}, \gamma)$ cross sections resulted in more ${ }^{240} \mathrm{Pu}$ than for the same calculation performed using ENDF/B-VII.0 data, caused by increased production via the path ${ }^{239} \mathrm{~Np} \rightarrow{ }^{240} \mathrm{~Np} \rightarrow{ }^{240} \mathrm{Pu}$.

The differences between the EAF-2003 and ENDF/B-VII.0 neutron cross sections for ${ }^{239} \mathrm{~Np}$ are attributed mostly to differences in the resonance region $(\sim 1-100 \mathrm{eV})$. There are no resonance integral measurements for ${ }^{239} \mathrm{~Np}$ capture in the literature. EAF-2003 uses a nuclear model to predict the resonance integral and uses a single resonance approximation to represent the resonance cross sections. ENDF/B-VII.0 does not include any resonance information in the cross section evaluation.

To assess the impact of the ${ }^{239} \mathrm{~Np}$ nuclear data, the computational models for the analysis of Hanford B reactor PTA-069 and PTA-084 experiments were updated to replace the ENDF/BVII.0 cross sections for ${ }^{239} \mathrm{~Np}$ with EAF-2003, ENDF/B-VII.1, or TENDL cross sections. The cross sections for all other nuclides, which are based on ENDF/B-VII.0, were not changed.

The effect of the change in ${ }^{239} \mathrm{~Np}$ cross sections on the calculated isotopic content for ${ }^{240} \mathrm{Pu}$ is illustrated in Fig. 30. The figure shows the change in ${ }^{240} \mathrm{Pu}$ relative to the base case calculated using ENDF/B-VII.0. There is little effect when the TENDL data are used in lieu of the ENDF/BVII.0 data. However, there is an increase in the calculated ${ }^{240} \mathrm{Pu}$ content when the EAF-2003 data or the ENDF/B-VII.1 data are used, with the magnitude of the change decreasing with burnup. When the EAF-2003 data are used, the calculated ${ }^{240} \mathrm{Pu}$ content increases by $\sim 1-5 \%$. The magnitude of the increase is smaller, up to $\sim 2 \%$, when the ENDF/B-VII.1 data are used. However, these changes $(<5 \%)$ do not resolve the large consistent underpredictions $(50 \%)$ observed for ${ }^{240} \mathrm{Pu}$ in the very low burnup Hanford samples. 


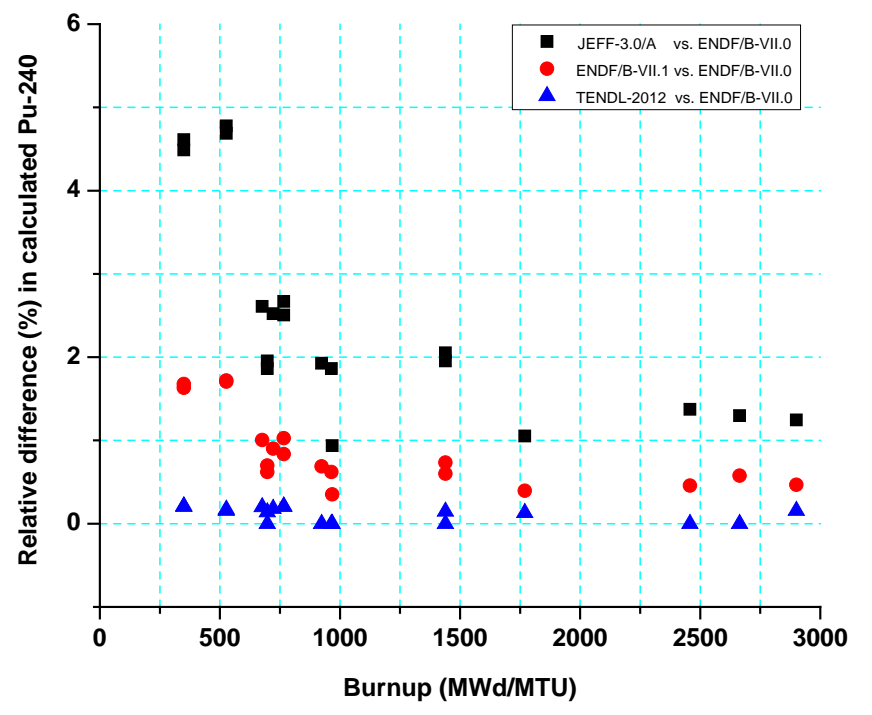

Fig. 30. Effect of ${ }^{239} \mathrm{~Np}$ cross section on calculated ${ }^{240} \mathrm{Pu}$ content.

These findings indicate potentially serious ENDF/B-VII data deficiencies that are important to low exposure plutonium production scenarios. This possible deficiency is not unique to ENDF/BVII and is observed for other sources of nuclear data reviewed in this study. This deficiency can be traced to a lack of adequate cross-section measurements for this nuclide. The ENDF/B-VII evaluated data for ${ }^{239} \mathrm{~Np}$ thermal neutron capture is based on measurements performed in 1959 [27]. An initial review of these experiments suggests that the state of knowledge of nuclear data at the time could have contributed to large uncertainties in the cross sections measured by these early experiments. A careful reevaluation of the early experiments is warranted, and data from the Hanford B and other more recent experiments on low-exposure irradiations could provide a basis for an improved cross-section measurement.

The experimental data from the Hanford B experiments provide a potentially valuable benchmark to validate both the nuclear data and the physics models. 


\section{SUMMARY}

Investigations were performed to provide a preliminary evaluation of benchmarks relevant to experiments performed in 1967 at the Hanford B reactor. Two of the experiments were analyzed in this report: PTA-069, which was designed to study the production of ${ }^{237} \mathrm{~Np}$ from natural uranium with a high ${ }^{236} \mathrm{U}$ content and PTA-084, which was designed to study the extended production exposures. These experiments involved 19 samples selected from 6 irradiated fuel tubes. The measurement data are relevant to investigating production of weapons-grade plutonium from natural uranium fuel in graphite-moderated, water-cooled systems.

Computational models have been developed for the Hanford B experiments using the SCALE code system. The following production responses have been calculated: uranium and plutonium isotopic compositions, production of total plutonium, production of total neptunium, cesium production, depletion of ${ }^{235} \mathrm{U}$, and buildup of ${ }^{236} \mathrm{U}$. The comparison of calculated and measured data has served to evaluate both the experimental data and modeling data quality, and has served to identify specific, additional modeling information and data needs. These data needs include more detail of the operating/irradiation history for the measured samples, better estimates of the fuel element exposures, and additional information on the measurement techniques and associated uncertainties. The existing data and documentation have the potential to become a quality benchmark that could serve for validation of computer codes and associated nuclear data.

Further studies to improve the estimates of element burnup using alternate measurement data and computational methods (e.g., actinide measurements and cesium production results) are continuing. A thorough sensitivity and uncertainty analysis of the benchmarks is planned, using the new uncertainty analysis tools available in SCALE, to determine the impact of known uncertainties and unknown parameters on the metrics of interest.

An important finding of this preliminary analysis is the identification of an apparent nuclear data deficiency important to low-exposure production irradiations. Further work to clarify the cause of significant underpredictions in ${ }^{240} \mathrm{Pu},{ }^{241} \mathrm{Pu}$, and ${ }^{242} \mathrm{Pu}$ using state-of-the-art nuclear ENDF/BVII.1 cross-section data is needed. These studies should be coordinated with the nuclear data community to help assess the quality of existing cross section-data required for production simulations and to develop data needs for the future. 


\section{REFERENCES}

1. R. J. Puigh and H. Toffer, "Potential Benchmarks for Actinide Production in Hanford Reactors," CHPRC-01590 Revision 0, CH2M HILL report, Richland, WA (October 2011).

2. R. J. Puigh and S. H. Finfrock, "Actinide Cross-Section Data Summary for the U-Pu Reaction Chain”, PRC-NS-00049, Revision 0, CH2M HILL report, Richland, WA (May 2013).

3. J. P. Schmitt and H. Toffer, "PTA-069 - Neptunium-237 Production from Natural Uranium with a High U-236 Content, DUN-2441, Douglas United Nuclear, Inc, Richland, WA (May 1967).

4. H. Toffer and A. F. Kupinski, "Experimental Isotopic Analysis of Point Exposure Data in Hanford Production Reactor Fuels”, DUN-7243, Douglas United Nuclear, Inc, Richland, WA (September 1970).

5. H. Toffer and S. P. Roblyer, "Hanford Site Production Data Pertinent to Actinide Burning”, Proceedings, GLOBAL’93, Seattle, WA (September 1993).

6. H. Toffer, Quarterly Letter Report (undated).

7. http://en.wikipedia.org/wiki/Hanford_Site

8. B. D. Murphy, "ORIGEN-ARP Cross-Section Libraries for Magnox, Advanced GasCooled, and VVER Reactor Designs,” ORNL/TM-2003/263, Oak Ridge National Laboratory, Oak Ridge, TN (2004).

9. http://webbook.nist.gov/chemistry/fluid/

10. “Monthly Report October 1967”, DUN-3179, Douglas United Nuclear, Inc, Richland, WA (November 20, 1967).

11. “Monthly Report November 1967”, DUN-3180, Douglas United Nuclear, Inc, Richland, WA (December 15, 1967).

12. ARIANE International Programme-Final Report, ORNL/SUB/97-XSV750-1, Oak Ridge National Laboratory, Oak Ridge, Tennessee (May 1, 2003).

13. "SCALE: A Comprehensive Modeling and Simulation Suite for Nuclear Safety Analysis and Design, ORNL/TM-2005/39, Version 6.1, Oak Ridge National Laboratory (2011). Available from Radiation Safety Information Computational Center at Oak Ridge National Laboratory as CCC-785.

14. S. M. Bowman, "SCALE 6: Comprehensive Nuclear Safety Analysis Code System," Nuclear Technology 174 (2), 126-148 (2011).

15. M. B. Chadwick et al., "ENDF/B-VII.0: Next Generation Evaluated Nuclear Data Library for Nuclear Science and Technology,” Nuclear Data Sheets, 107, 2931-3060 (2006). 
16. M. D. DeHart and S. M. Bowman, "Reactor physics methods and analysis capabilities in SCALE”, Nuclear Technology 174 (2), 196 (2011).

17. I. C. Gauld, G. Radulescu, G. Ilas, B. D. Murphy, M. L. Williams, and D. Wiarda, "Isotopic Depletion and Decay Methods and Analysis Capabilities in SCALE," Nuclear Technology 174(2), 169-195 (2011).

18. J-Ch Sublet, A. J. Koning, R. A. Forrest and J. Kopecky, “The JEFF-3.0/A Neutron Activation File-EAF-2003 into ENDF-6 Format”, Commissariat à l'Energie Atomique, France, JEFDOC-982 (2003). Data available from http://www.nea.fr/html/dbdata/JEFF/.

19. M. B. Chadwick et al, "ENDF/B-VII.1 Nuclear Data for Science and Technology: Cross Sections, Covariances, Fission Product Yields and Decay Data,” Nuclear Data Sheets, 112, 2887-2996 (2011).

20. G. Ilas, I. C. Gauld, and G. Radulescu, "Validation of new depletion capabilities and ENDF/B-VII data libraries in SCALE,” Annals of Nuclear Energy 46, $43-55$ (2012).

21. B. D. Murphy, "ORIGEN-ARP Cross-Section Libraries for the RBMK-1000 System," ORNL/TM-2006/139, Oak Ridge National Laboratory (2006).

22. G. Ilas, B. D. Murphy, and I. C. Gauld, "Overview of ORIGEN-ARP and its Applications to VVER and RBMK," ANS Transactions 97, 601-603 (2007).

23. J. Halperin, R. W. Stoughton, C. M. Stevens, D. E. Ferguson and D. C. Overholt, “An effective capture cross section of ${ }^{239} \mathrm{~Np}$ for thermal reactor neutrons”, Nuclear Science and Engineering 1, 108-111 (1956).

24. I. C. Gauld, M. T. Pigni, G. Ilas, and D. Wiarda" Integral Testing of the 239Np Capture Cross Section using Reactor Experiments”, presentation at the Cross Section Evaluation Working Group Meeting (CSEWG), New York (November 2013).

25. A. J. Koning, D. Rochman, S. van der Marck, J. Kopecky, J. Ch. Sublet, S. Pomp, H. Sjostrand, R. Forrest, E. Bauge and H. Henriksson, "TENDL-2012: TALYS-based evaluated nuclear data library", www.talys.eu/tendl-2012.html .

26. S. F. Mughabghab, Atlas of neutron resonances resonance parameters and thermal cross sections Z=1-100, Elsevier (2006).

27. R. W. Stoughton and J. Halperin, "Heavy Nuclide Cross Sections of Particular Interest to Thermal Reactor Operation: Conventions, Measurements and Preferred Values”, Nuclear Science and Engineering. 6, 100-118 (1959). 
APPENDIX A.

ADDITIONAL DATA NEEDS FOR HANFORD B EXPERIMENTS EVALUATION 



\section{APPENDIX A. ADDITIONAL DATA NEEDS FOR HANFORD B EXPERIMENTS EVALUATION}

\section{A.1 EXPERIMENTAL DATA}

To enable a better assessment of the measurement data quality and more insight in the comparison calculation-experiment, availability of primary assay measurements would be needed. Related specific needs are listed subsequently. Some items on the list might be addressed in these primary references.

\section{Cooling time - decay time from discharge from reactor to date when measurements} were performed

Calculated data for $\mathrm{Pu}, \mathrm{Np}$, or Cs production, and Pu isotopic composition are affected. The measurements for some nuclides are affected by the cooling time, caused by ingrowth from decay precursors in the actinide decay chains and by decay of the measured actinide (e.g., ${ }^{241} \mathrm{Pu}$ ). In addition, the ${ }^{137} \mathrm{Cs}$ content would be affected; though the expected change in this isotope is not large, it would however impact its usage as a burnup indicator.

2. How the reported Cs content was measured (mass spectrometry after separation, gamma spectrometry, etc.)? Which isotopes of cesium are included in the reported "Cs production” measurement data? At discharge time, significant contributors are ${ }^{133} \mathrm{Cs}$, ${ }^{134} \mathrm{Cs},{ }^{135} \mathrm{Cs}$, and ${ }^{137} \mathrm{Cs}$. Based on the analysis in the current report, it is likely that the measured data refers to ${ }^{137} \mathrm{Cs}$ or $\left({ }^{137} \mathrm{Cs}+{ }^{134} \mathrm{Cs}\right)$.

3. Does the "ton U" used as basis to report measurement data refer to mass of initial uranium (before irradiation) or the mass of uranium at the time of measurement (after irradiation)?

Depending on the sample exposure, the total mass of uranium at discharge can vary by up to $0.5 \%$ compared with initial uranium mass. Does the basis used include the cladding, or only the uranium? Clarification on the mass basis is needed - could potentially contribute to up to $0.5 \%$ to the $\mathrm{C} / \mathrm{E}$ data estimated by simulation. This might be revealed by primary assay reports.

4. Is the provided uncertainty a 1, 2, or 3 sigma uncertainty (what is the confidence level)?

Given the small values for the reported uncertainties, it seems likely that they are 1 sigma.

5. Were the two sets of measurement data reported for samples \#5 and \#6 obtained using the same physical samples that were measured at two different times? Or do they correspond to measurements of two samples cut from the same fuel element? It is mentioned that the fuel samples (radial discs 1/16 in thick) were typically cut from the center of the fuel element. 


\section{A.2 MODELING DATA}

\section{A.2.1. Material Data}

1. Density of uranium or total mass of uranium in the fuel element before irradiation. The initial total mass of uranium in fuel element was derived as $7.13 \mathrm{lb}$, based on available geometry data, fuel element configuration, and total weight of the fuel element provided as $7.43 \mathrm{lb}$ (this weight seems to include the cladding). This derived mass is equivalent to a density of uranium metal of $18.06 \mathrm{~g} / \mathrm{cm}^{3}$. Note that the uranium theoretical density is $19.1 \mathrm{~g} / \mathrm{cc}$, and typical values of uranium metal density reported for MAGNOX fuel is about $18.9 \mathrm{~g} / \mathrm{cc}$, so there is uncertainty here with the derivation.

2. Density of graphite and its impurity content (may be equivalent boron) or type and source of graphite.

Assumption used - pure graphite (no impurities) with density $1.7 \mathrm{~g} / \mathrm{cm}^{3}$.

\section{A.2.2. Operation/Irradiation History Data}

1) Significance of provided tube average power in $k W$ and provided estimated exposure in MWd/ton.

Apparently the provided values are inconsistent. Finding more information on how the average tube power was estimated would help in clarification. If the average tube power value in $\mathrm{kW}$ is used as a start point, the average tube exposure calculated based on this in units of MWd/ton fuel element ( 0.1189 ton fuel - uranium +aluminum per fuel element) is $6-7 \%$ smaller for all of the five tubes. The similarity of the ratio between the provided and the estimated exposure for all five tubes (1.06-1.07) would potentially indicate an inconsistency in units or geometry data used (tube length or active tube length?) for derivation.

2) Clarification of the basis used for provided exposure data.

What does this mass basis (ton) refer to? Is it the total weight of the tube; the $\mathrm{Al}+\mathrm{U}$ mass for a fuel element multiplied by the number of fuel elements in a tube; or the mass for the active region (8.378 in length) of the fuel element multiplied by the number of fuel elements in the tube?

3) What is the length basis for the specific power in $\mathrm{kW} / \mathrm{ft}$ provided for each fuel element? Does the length ( $\mathrm{ft}$ ) refer to the length of the active region (8.378 in) of the fuel element or to the overall fuel element length (8.965 in)? 